\title{
Virtual Design in Organic Electronics: Screening of a Large Set of 1,4- Bis(phenylethynyl)benzene Derivatives as Molecular Semiconductors
}

\author{
Authors \\ Mónica Moral, ${ }^{1,{ }^{*}}$ Andrés Garzón, ${ }^{2}$ Miguel Castro, ${ }^{1}$ Jesús Canales-Vázquez, ${ }^{1}$ Juan Carlos Sancho-García, ${ }^{3}$ \\ ${ }_{1}^{1}$ Renewable Energy Research Institute, University of Castilla-La Mancha, Paseo de la Investigación 1, 02071 , \\ Albacete, Spain \\ 2 Department of Physical Chemistry, Faculty of Pharmacy, University of Castilla-La Mancha, Cronista Francisco \\ Ballesteros Gómez, 1, 02071, Albacete, Spain \\ ${ }^{3}$ Department de Physical Chemistry, Faculty of Chemistry, University of Alicante, 03080, Alicante, Spain
}

\begin{abstract}
In this work, we have theoretically studied the electronic properties of a large series of 1,4bis(phenylethynyl)benzene derivatives, with the chemical formula $Y-C \equiv C-X-C \equiv C-Y$, being $X$ and $Y$ aromatic rings and chosen to act as donor and acceptor moieties. Employing state-of-the-art DFT calculations, we have analyzed a set of relevant electronic properties related to the optoelectronic and semiconductor character of these systems, namely molecular and energy levels, electron affinity, ionization potential, reorganization energy and electronic coupling between neighboring molecules forming dimers, obtained after evaluation of binging energy landscapes. The latter energy magnitude needed to disclose first the favoured intermolecular interactions (i.e. the lowest binding energy) to concomitantly estimate the charge transport rates next. The systematic screening performed allowed us to anticipate the possible use of some of these derivatives as $p$-type, $n$-type or even ambipolar organic molecular semiconductors.
\end{abstract}




\section{INTRODUCTION}

Conjugated rod-like (i.e quasi one-dimensional) molecules have been widely studied for their use in the development of molecular electronic devices such as wires, switches or insulators. ${ }^{1}$ One of the most suscessful candidates is the family of organic compouds derived from 1,4-bis(phenylethynyl)benzene (BPEB), which could thus be employed in the field of molecular electronics due to their good luminescence and efficient charge transport properties. ${ }^{2-5}$ These compounds show interesting electronic properties related, in part, to the axial symmetry of ethynylene groups, which allow to fine-tune the degree of conjugation between adjacent aryl groups at different relative orientations thank to rotational barriers as small as $1 \mathrm{kcal}$ $\mathrm{mol}^{-1}$ between the end moieties. ${ }^{4-9}$ In the last years, different electron-withdrawing and electron-donating aromatic rings have been incorporated within the generic BPEB structure to modify their light-emitting properties, and improve charge injection and transport efficiency concomitantly. ${ }^{10-20}$ Moreover, the effect of the ethynylene group on electronic properties have also been studied extensively by means of Density Functional Theory (DFT) calculations. ${ }^{7,8,21}$ The information derived from these calculations can be useful to guide the chemical synthesis of new BPEB derivatives.

With this background in mind, the aim of this work is to obtain new insights into the electronic properties of BPEB derivatives. To this extent, a set of key energy magnitudes related to semiconducting properties were calculated for a very large set of $(x 100)$ BPEB derivatives. Diverse electron-withdrawing (acceptor, A) and electron-donating (donor, D) aromatic rings were combined to generate a large set of compounds connected by a ethylylene moiety, with a generic formula $Y-C \equiv C-X-C \equiv C-Y$, being $X$ and $Y$ aromatic rings collected in Chart 1 . The internal triple bonds in organic systems such as small compounds or polymers, has been widely used to extend the conjugation and hence make more rigid backbones for pronounced intrachain interactions. This strategy has been widely employed for instance to design low band gap polymers for solar cell applications. ${ }^{22}$ Therefore, in orden to obtain the most suitable compounds for optoelectronic applications, we have selected as central moiety both m-electron defficient rings, such as thiazolo[5,4-d]thiazole ( 2 compounds), s-tetrazine ( 3 derivetives) and pyridine (4 derivatives), or electrondonor rings such as thieno[3,2-b]thiophene ( 1 derivatives) or benzene ring ( 5 compounds), which have been widely used in other opto-electronic devices. ${ }^{23}$ These groups will be combined with some $\pi$-excedent heterocycles such as pyrrole, furan or thiophene, some fluorene and carbazole derivatives, and finally anthracene and phenanthrene derivatives. To achieve this goal, we present first the theoretical methodology to be employed, considering the trade-off between the accuracy of the results and their computational cost, and we will show next the study of their semiconductor properties, by changing the $D$ and $A$ groups, thus attempting to set up their promising role in the fabrication of devices, acting as $p$-type, $n$-type and, possibly, as ambipolar semiconducting active materials. 


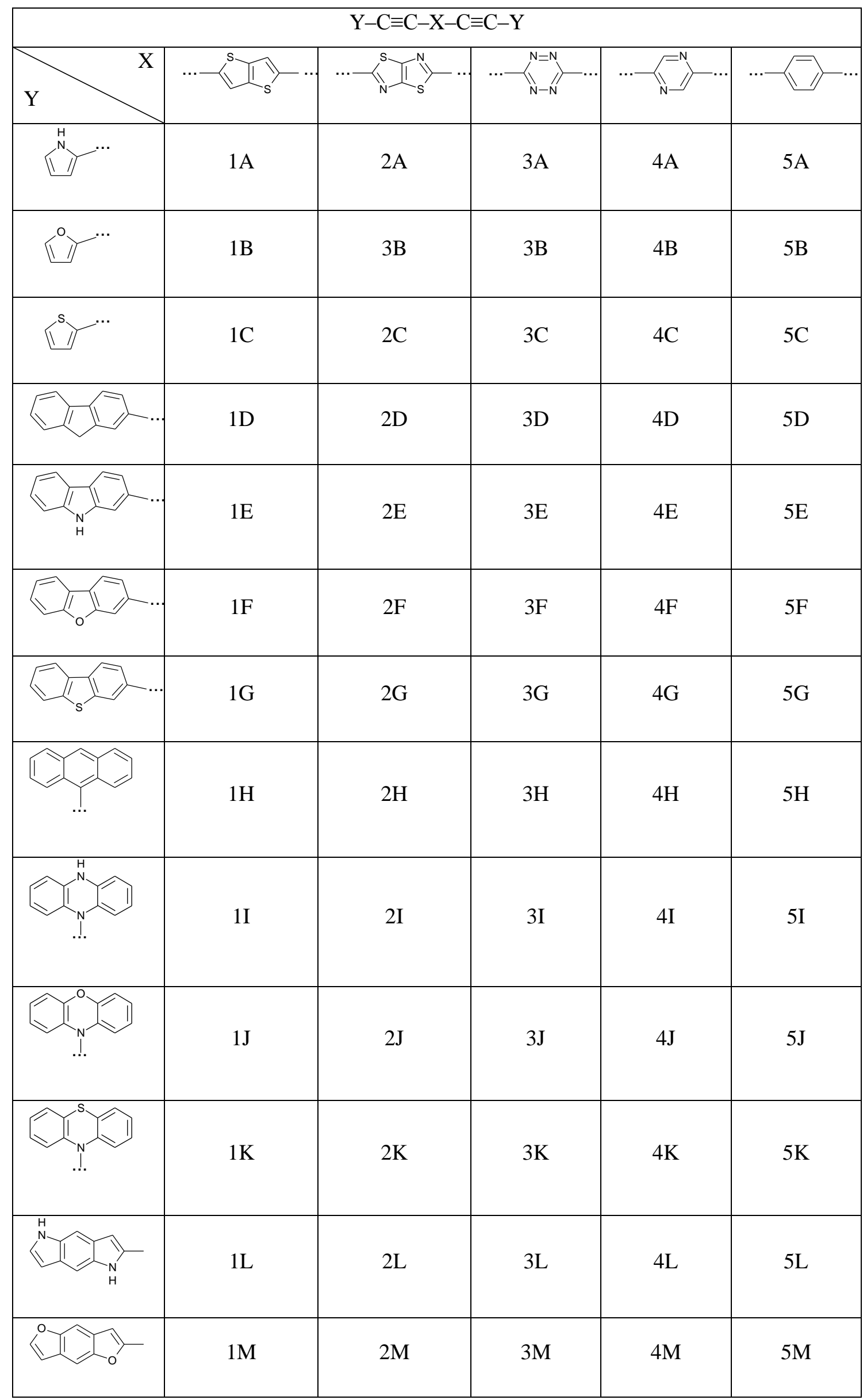




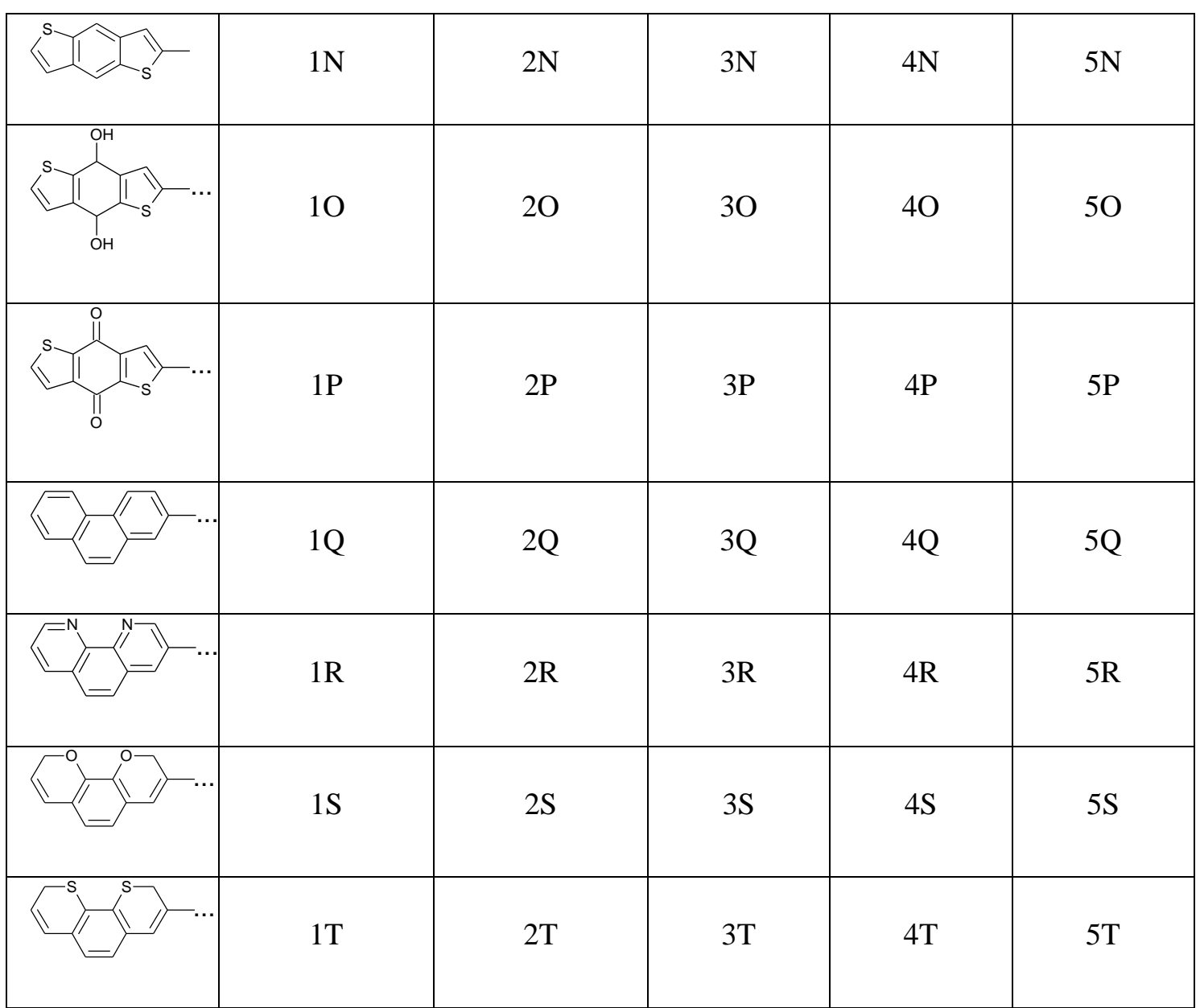

Chart 1. Selected BPEB derivatives for this study, showing the bonding pattern, and the notation followed.

\section{THEORETICAL FRAMEWORK}

The performance of optoelectronic devices greatly depends on an efficient charge injection and an associated high mobility. In typical m-conjugated organic (crystalline) materials with small bandwidths $(\ll<1$ $\mathrm{eV}$ ) at room temperature, and strong electron-phonon coupling, charge motion is generally described by a hopping mechanism, allowing the self-migration of the charge carriers along the lattice.24-27 The corresponding charge transfer rate can be calculated through the Marcus-Levich-Jortner (MLJ) model27-29

$k_{C T}=t_{12}^{2} \sqrt{\frac{\pi}{\hbar^{2} k_{B} T \lambda_{\mathrm{e}}}} \sum_{n=0}^{\infty}\left\{\exp \left(-S_{\text {eff }}\right) \frac{\left(S_{\text {eff }}\right)^{n}}{n !} \exp \left[\frac{-\left(\lambda_{\mathrm{e}}+v \hbar \omega_{\text {eff }}+\Delta G^{0}\right)^{2}}{4 \lambda_{\mathrm{e}} k_{B} T}\right]\right\}$

where $k_{B}$ and $\hbar$ are Boltzmann and Planck constants, respectively; $T$ is the temperature, fixed in the present work at $300 \mathrm{~K} ; \Delta \mathrm{G}^{0}$ is the free energy difference between the electronic states involved in the charge transfer process (equal to zero for an ideal self-exchange process); while $\lambda_{\mathrm{e}}$ and $t_{12}$ correspond with the classical contribution (mostly external) to the reorganization energy $21,30-32$ and the charge transfer integral, respectively.

In the MLJ model, we assume that the reorganization energy, $\lambda$, can be calculated as sum of two different contributions: the external, $\lambda_{\mathrm{e}}$, and internal, $\lambda_{\mathrm{i}}$, terms, $\left(\lambda=\lambda_{\mathrm{i}}+\lambda_{\mathrm{e}}\right)$. The normal modes responsible for the $\lambda_{e}$ are typically very low frequency modes $\left(\hbar \omega_{\text {eff }} \ll k_{B} T\right)$ which can be treated classically. ${ }^{27,33}$ 
Furthermore, in organic molecular crystals, the outer contribution, $\lambda_{\mathrm{e}}$, is of the order of one tenth of $\mathrm{eV}, 33,34$ contrary to charge transfer in solution, wherein higher values are expected. $27,33,35-38$ Different values for $\lambda_{\mathrm{e}}$, ranging between 0.01 and $0.2 \mathrm{eV}$, have been proposed and employed in the literature so far. ${ }^{33,39-41}$ In that sense, we prefer to keep that values fixed here at $0.1 \mathrm{eV}$ in order to facilitate the comparison with previous rate constants reported before for related compounds. ${ }^{21,30-32}$ Conversely, the intramolecular high frequency vibrational modes responsible for $\lambda_{i}$ are typically quantum modes $\left(\hbar \omega_{\text {eff }}>k_{B} T\right.$, where $\omega_{\text {eff }}$ incorporates, in an average way, the effects of all these modes, and it is calculated as $\omega_{e f f}=\frac{\sum_{i} \omega_{i} S_{i}}{\sum_{i} S_{i}}$, being $\omega_{\mathrm{i}}$ the corresponding vibrational frequency and $S_{i}$ represents the Huang-Rhys factor for $i$ mode). Note that $S_{\text {eff }}$ is the effective Huang-Rhys factor, which is a measure of the electron-vibrational coupling (calculated as $S_{\text {eff }}$ $=\lambda_{i} / \hbar \omega_{\text {eff }}{ }_{3}{ }^{37,42-44}$ In this work, $\hbar \omega_{\text {eff }}$ has been fixed at $0.2 \mathrm{eV}$, which corresponds to the typical energy of $\mathrm{C}-\mathrm{C}$ and $\mathrm{C}=\mathrm{C}$ stretching modes. ${ }^{41,45,46}$ With this approximation, $k_{C r}$ is correspondingly treated at the quantummechanical level via the effective Huang-Rhys factor. ${ }^{44,47,48}$

Notwithstanding some limitations inherent to the MLJ model due to the approximations used in the determination of $k_{C T}$, such as $t_{12}<<$, there are two energy magnitudes controlling, from a semiquantitative point of view, the charge transport in organic compounds, being both the reorganization energy and the charge transfer integral. As mentioned above, the reorganization energy can be divided in two contributions: the internal one (which includes only the reorganization energy of the molecules involved in the charge transfer) and the external one (which accounts for any environmental relaxation and changes upon charge hopping) which is fixed at $0.1 \mathrm{eV}$. The internal reorganization energy, $\lambda_{\mathrm{i}}$, consists of two terms corresponding to the geometry relaxation energies upon going from the neutral-state geometry to the charged state and vice versa (also known as Nelsen's four-point method) ${ }^{49,50}$

$$
\begin{aligned}
& \lambda_{i}=\lambda_{1}+\lambda_{2} \\
& \lambda_{1}=E^{0}\left(G^{*}\right)-E^{0}\left(G^{0}\right) \\
& \lambda_{2}=E^{*}\left(G^{0}\right)-E^{*}\left(G^{*}\right)
\end{aligned}
$$

where $E^{0}\left(G^{0}\right)$ and $E^{*}\left(G^{*}\right)$ are the ground-state energies of the neutral and ionic states, respectively; $E^{0}\left(G^{*}\right)$ is the energy of the neutral molecule at the optimized ionic geometry and $E^{*}\left(G^{0}\right)$ is the energy of the charged molecule at the optimized neutral geometry. ${ }^{26,27,37}$

The charge-transfer integral, $t_{12}$, reflects the strength of the electronic coupling between neighboring molecules, and therefore critically depends on their relative spatial arrangement and is defined by the matrix element

$$
t_{12}=\left\langle\psi_{1}|\hat{\mathrm{H}}| \psi_{2}\right\rangle
$$

where $\hat{H}$ is the electronic Hamiltonian of the whole system and $\psi_{1}$ and $\psi_{2}$ are the wavefunctions of both initial and final charge localized states. ${ }^{25,26,38}$ The charge transfer integral has been calculated within the fragment approach at the DFT level implemented in the Amsterdam Density Functional (ADF) package. ${ }^{51}$ In this approach, the orbitals of the dimer are expressed as a linear combination of the molecular orbitals (MOs) of the individual units, i.e. fragments that are obtained solving the Kohn-Sham equations. Since the fragment 
orbitals form a non-orthogonal basis set, the corresponding transfer integral depends on the choice of the energy origin so that the transfer integral is no longer an invariant. The problem is solved by applying a Löwdin transformation to the initial electronic Hamiltonian and the charge transfer integral $t_{12}$ is finally obtained by

$$
t_{12}=\frac{\widetilde{t_{12}}-\frac{1}{2}\left(\varepsilon_{1}+\varepsilon_{2}\right) S_{12}}{1-S_{12}^{2}}
$$

where $\tilde{t}_{12}, \varepsilon_{i}$ and $S_{12}$ are the transfer integral $\left(\left\langle\psi_{1}|\hat{\mathrm{H}}| \psi_{2}\right\rangle\right)$, the site energies $\left(\left\langle\psi_{i}|\hat{\mathrm{H}}| \psi_{i}\right\rangle\right)$ and the overlap matrix element $\left(\left\langle\psi_{1} \mid \psi_{2}\right\rangle\right)$ defined in the non-orthogonal basis set. ${ }^{21}$

Once $k_{c T}$ has been calculated, it is possible to estimate the charge hopping mobility, $\mu_{\text {hop }}$, through the Einstein-Smoluchowski relationship. The homogeneous charge diffusion coefficient, $D$, can be previously calculated assuming an $n$-dimensional and spatially isotropic system as

$$
D=\frac{1}{2 n} \lim _{t \rightarrow \infty} \frac{\left\langle r^{2}\right\rangle}{t} \approx \frac{1}{2 n} \sum_{i} r_{i}^{2} k_{i} p_{i}
$$

where $n$ is the number of dimensions taking account (in that case, only one dimension will be considered hereafter) and $i$ runs over all nearest adjacent molecules, whereas $r_{i}$ and $k_{i}$ are the corresponding center-tocenter hopping distance and the electron-transfer rate constant respectively. Finally, $p_{i}\left(p_{i}=\frac{k_{i}}{\sum_{i} k_{i}}\right)$ is the hopping probability, ${ }^{25,52-54}$ which will be set here to $p_{i}=1$ in all cases. Since the crystal structure of the studied molecules remains unknown, we will only focus on the study of the charge transport along an ideal onedimensional array of molecules with intermolecular distance $r\left(n=1, p_{i}=1\right)$ and, hence, eq. (7) can be simplified to $D=(1 / 2) \mathrm{r}^{2} \mathrm{k}_{\text {CT. }}$. In short, in the zero field limit, the charge carrier mobility can be obtained as easily as follows:

$$
\mu_{\text {hop }}=\frac{e D}{k_{B} T}=\frac{e r^{2} k_{C T}}{2 k_{B} T}
$$

where $e$ is now the elementary charge..$^{25,52-54}$

Concerning the process of charge injection from an electrode to the organic semiconductor, two molecular descriptors are commonly used to evaluate the efficiency of this process: (i) the energy difference between the Highest Occupied (HO)MO or Lowest Unoccupied (LU)MO energy levels ( $E_{\text {HOMo/ }} / E_{L U M O}$ ) of the organic semiconductor and the work function $\left(\Phi_{\mathrm{m}}\right)$ of the electrode, and (ii) the molecular ionization potential/electron affinity (IP/EA). The metal-semiconductor interface is usually treated as a Mott-Schottky barrier, where the barrier height is given by the difference between $\Phi_{m}$ and the semiconductor HOMO or LUMO energy level. ${ }^{35,55,56}$ However, neglecting necessarily interface dipole effects between electrode and semiconductor, ${ }^{33,57}$ we will always compare $\Phi_{\mathrm{m}}$ with $\mathrm{E}_{\text {номо }} \mathrm{E}_{\text {Lumo }}$ energy levels of the semiconductor, to find out the likeliness of charge injection and the magnitude of the contact resistance. Moreover, the values of $\mathrm{E}_{\text {номо }}\left(\mathrm{E}_{\text {LUMо }}\right)$ must range between $-4.8 \mathrm{eV}$ and $-5.5 \mathrm{eV}(-3.6 \mathrm{eV}$ and $-4.5 \mathrm{eV})$ to ensure and enhance the stability of the optoelectronic device. ${ }^{37}$ On the other hand, IP and EA are also key parameters to predict the efficiency of the injection of charges from the electrodes as well as the ease to be reduced or oxidized upon air exposure..$^{58}$ There is a general agreement that materials showing low IP and low AE may act as p-type semiconductors, while systems with high EA and high IP may behave as electron-acceptor compounds. ${ }^{59}$ 
Moreover, it is widely accepted that EA of a semiconductor should be at least $3.0 \mathrm{eV}$ to allow easy electron injection, but lower than $4.0 \mathrm{eV}$ because of the negative charges can react with atmospheric oxidants such as water or oxygen. ${ }^{35,60-62}$ However, its stability in ambient conditions could be compromised by other factors such as the crystal packing and film morphology. ${ }^{35,63-65}$ Low IPs facilitate hole injection but too low values can produce unintentional doping. The adiabatic and vertical ionization potentials (AIP/VIP) and electron affinities (AEA/VEA) were calculated as follows for cationic state

$$
\begin{aligned}
& A I P=E_{0}\left(G_{0}\right)-E^{*}\left(G^{*}\right) \\
& V I P=A I P+\lambda_{2}
\end{aligned}
$$

and for the anionic state

$$
\begin{aligned}
& A E A=E_{0}\left(G_{0}\right)-E^{*}\left(G^{*}\right) \\
& V E A=A E A+\lambda_{2}
\end{aligned}
$$

where $\mathrm{E}_{0}\left(\mathrm{G}_{0}\right), \mathrm{E}^{*}\left(\mathrm{G}^{*}\right)$, and $\lambda_{2}$ are the same quantities appearing in eqs 3 and 4 .

\section{COMPUTATIONAL DETAILS}

The B3LYP functional - implemented in Gaussian09 (Revision D.01) ${ }^{66}$ — along with the basis set $6-31+G^{*}$ - especially recommended in calculations involving ionic species ${ }^{67}$ - was employed to optimize the geometry of all the selected compounds and estimate the different energies (Eномо / $E_{\text {LUMо }}, I P$ / EA and $\lambda_{\mathrm{i}}$ ). The nature of the minima was confirmed by means of the eigenvalues (all positive) of the corresponding Hessian matrices. Although Koopmans' theorem is not rigorously applicable to Kohn-Sham orbital energies, Perdew proved a connection between IP (EA) and HOMO (LUMO) energy values through Janak's theorem (see, e.g., refs [67] to [69])and references therein). In this sense, B3LYP has been proven to be accurate enough for predicting $E A s^{70,71}$ and provides theoretical $\lambda$ values in good quantitative agreement with the experimental values obtained from gas-phase ultraviolet photoelectron spectroscopy. ${ }^{72}$ Note that Zhang and Musgrave have also reported lower errors in the LUMO energy of small organic molecules with this method compared to other expressions with a higher percentage of exact-like exchange. ${ }^{73}$ In addition, M06-2X $X^{74}$ functional and $\mathrm{HF}^{75}$ method, along with B3LYP, were employed to study symmetry-broken effects in ionic states.

To calculate $t_{12}$ when the supramolecular structure of an organic crystal is unknown, we suppose a $\pi$-stacked arrangement since this geometrical arrangement is typically observed in BPEB derivatives. $5,6,16,17,21$ Consequently, to predict the most favorable orientation of molecules within the stack, we monitored the binding energy $\left(E_{b}\right)$ as a function of the relative $(x, y)$-displacement for a dimer built from two molecules keeping face-to-face planes and maintaining fixed the $3.5 \AA$ distance along the $z$-axis, which corresponds to a typical $\pi$-stacking distance ${ }^{76}$ (see Figure 1). Binding energy was calculated for each dimer as the energy difference between the dimer and the isolated monomers. Accordingly, while the position of one of the molecules has been kept fixed, the second one was displaced along $x$ - and $y$-axes in a grid of $1.0 \AA$ in both directions (see Figure 1). The M06-2X functional, ${ }^{74}$ together with the basis set $6-31 \mathrm{G}^{*}$, has been used for the calculation of the binding energy. It should be noted that although traditional DFT 
functionals perform poorly for non-covalent interactions, this functional has been shown to give reasonably accurate stacking geometries for a variety of dispersion dominated systems, such as perylenediimides and quaterthiophenes, ${ }^{77,78}$ DNA base pairs ${ }^{71}$ and some $s$-tetrazine derivatives, ${ }^{21}$ with the calculated binding energy yielding to similar results to those obtained with other (dispersion-corrected) functionals such as PBE0-dDsC/def2-SVP. ${ }^{78}$ Finally, $t_{12}$ has been calculated by using the ADF package with the LDA functional and the $\mathrm{DZ}$ basis set.

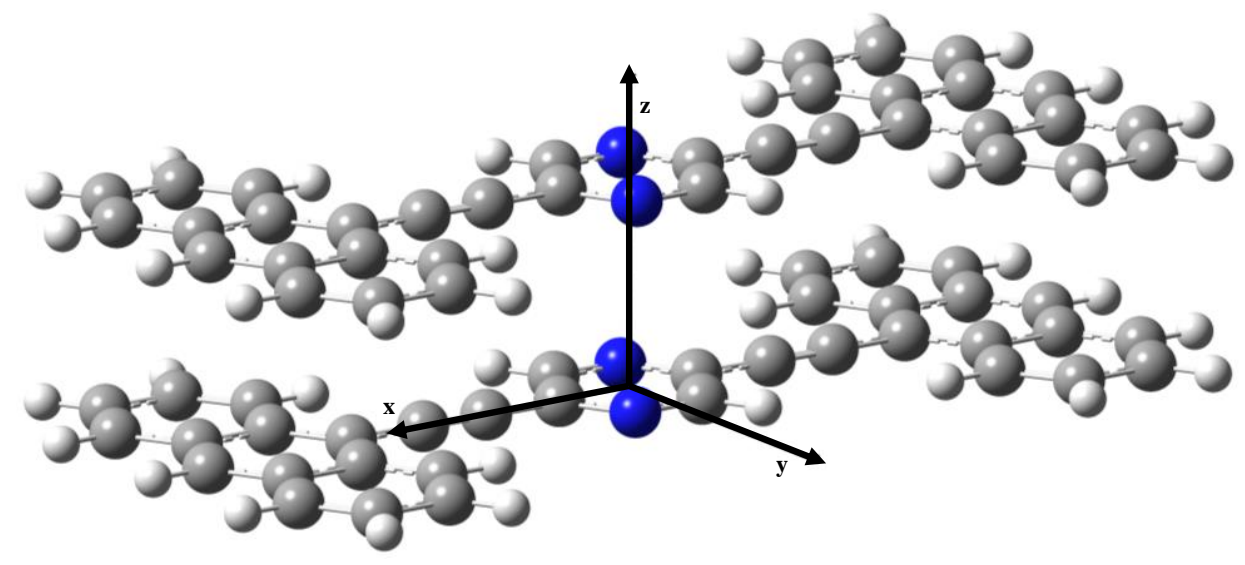

Figure 1. Example of a representative (4H) dimer in the position $x=0.0, y=0.0$, and $z=3.5 \AA$, where $(x, y, z)$ is the relative displacement between the central ring units along the long $(\mathrm{x})$ and short $(\mathrm{y})$ molecular axes and the $\pi$-stacking direction $(\mathrm{z})$, respectively.

\section{RESULTS AND DISCUSSION}

\section{Charge Injection Properties.}

The charge injection barrier has been defined as the difference between the energy of the frontier orbital (HOMO and LUMO) and the work function $\left(\Phi_{m}\right)$ of the metal injecting the charge (hole or electron) into the organic layers, and the ionization potential (IP) or electron affinity $(E A)$, depending on the nature of the semiconductor, i.e., $p$-type or $n$-type semiconductor. 33,57 To obtain a complete description of this behavior due to the interactions between the metal/organic interface, we should take into account the effect of the dipoles derived from either partial charge-transfer metal-semiconductor, the reduction of the $\Phi_{\mathrm{m}}$ by the organic layer, or the occupation of the metal-induced density of states in the gap of the organic material. ${ }^{80,81}$ However, the comparison between the free metal work function and the (gas-phase) HOMO (LUMO) energy levels could give us a qualitative guide for the hole (electron) barrier injection, and may let us to establish trends within a set of closely related compounds. ${ }^{21,30-32,46}$

Figure 2 shows the shape of HOMO and LUMO orbitals for some selected compounds (for other compounds, see Figure S1 in the Electronic Supporting Material, ESI), while Table 1 gathers the energy

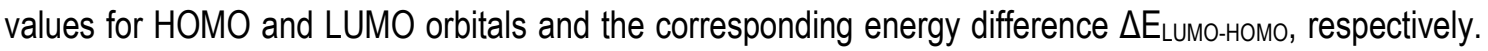
Due to the large variety of compounds studied, there are a wide range of energy values for HOMO and 
LUMO orbitals. The energy values range from $-4.28 \mathrm{eV}$ to $-6.86 \mathrm{eV}$ for $\mathrm{HOMO}$ orbital, and -1.47 to $-3.99 \mathrm{eV}$ for LUMO orbital. Obviously, these values are comparable to other state-of-the-art molecules such as tetracene $(-2.09$ and $-4.87 \mathrm{eV})$, pentacene $(-2.40$ and $-4.61 \mathrm{eV})$ or rubrene $(-2.09$ and $-4.69 \mathrm{eV}$ ) (see reference [82] and references therein) calculated at B3LYP/6-31G** level, or some halogenated rubicene derivatives or dibenzorubicene. ${ }^{46}$

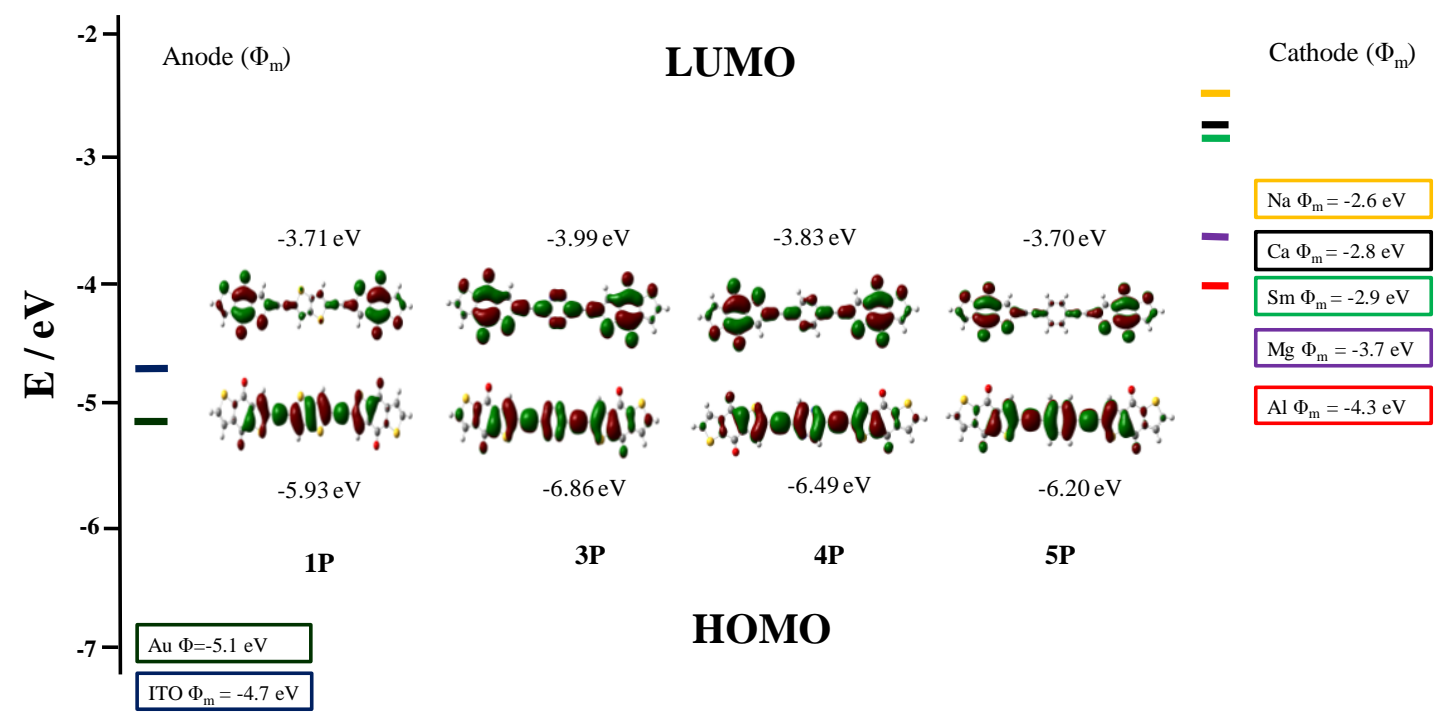

Figure 2. Isocontour plots $(0.02 \mathrm{au})$ and energy values of $\mathrm{HOMO}$ and $\mathrm{LUMO}$ orbitals for $1 \mathrm{P}, 3 \mathrm{P}, 4 \mathrm{P}$ and $5 \mathrm{P}$ compounds, calculated at the B3LYP/6-31+G* level, and the work function of the most commonly used electrodes in optoelectronic devices.

Regarding electron injection and the possible behavior of these compounds as $n$-type organic semiconductor, a good ohmic contact is generally expected when $\left|\Phi_{\mathrm{m}}-\mathrm{E}_{\mathrm{Lumo}}\right|<0.3 \mathrm{eV} .^{25}$ In general, all compounds, except $5 \mathrm{~A}, 5 \mathrm{I}, 5 \mathrm{~J}$ and $5 \mathrm{~K}$, satisfy the condition of an ohmic contact with one of the typically used electrodes, such as cesium ( $\left.\mathrm{Cs}, \Phi_{\mathrm{m}}=-2.1 \mathrm{eV}\right)$, sodium $\left(\mathrm{Na}, \Phi_{\mathrm{m}}=-2.6 \mathrm{eV}\right)$, calcium $\left(\mathrm{Ca}, \Phi_{\mathrm{m}}=-2.9\right.$ $\mathrm{eV})$, magnesium $\left(\mathrm{Mg}, \Phi_{\mathrm{m}}=-3.7 \mathrm{eV}\right)$ or aluminum $\left(\mathrm{Al}, \Phi_{\mathrm{m}}=-4.3 \mathrm{eV}\right) .{ }^{35,83}$ However, only the molecules with a thieno[2,3-f][1]benzothiophene-4,8-dione substituent $(\mathbf{P})$ in Y-position satisfy the range of accepted energy values for LUMO orbital in order to improve the stability of optoelectronic devices. ${ }^{37}$ These compounds, with

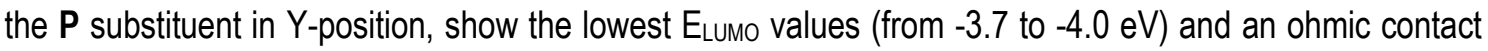
could be possibly formed with $\mathrm{Mg}$ electrodes $\left(\Phi_{\mathrm{m}}=-3.7 \mathrm{eV}\right) .{ }^{35,83}$ Considering the substituent in X-position, low $E_{\text {Lumo }}$ values $(\leq-3.0 \mathrm{eV}$ ) were, in general, calculated for s-tetrazine derivatives $(3 \mathrm{C} / 3 \mathrm{G} / 3 \mathrm{H} / 3 \mathrm{M} / 3 \mathrm{~N} / 3 \mathrm{O} / 3 \mathrm{P} / 3 \mathrm{R})$. Consequently, the lowest $\mathrm{E}_{\text {Lumo }}$ value was observed for the compound involving both previously mentioned rings, i.e. $3 \mathbf{P}$.

In the case of hole injection, all compounds satisfy the ohmic contact condition, i.e. $\left|\Phi_{m}-E_{\text {номо }}\right| \leq$ $0.3 \mathrm{eV}$, with some of the traditional cathode electrodes, such as Indium Tin Oxide (ITO, $\left.\Phi_{\mathrm{m}}=-4.7 \mathrm{eV}\right),{ }^{84}$ gold electrode $\left(\mathrm{Au}, \Phi_{\mathrm{m}}=-5.1 \mathrm{eV}\right), 83,84$ or some metal oxides such as $\mathrm{WO}_{3}\left(\Phi_{\mathrm{m}}=-6.8 \mathrm{eV}\right), \mathrm{MoO}_{3}\left(\Phi_{\mathrm{m}}=-6.8\right.$ $\mathrm{eV}), \mathrm{NiO}\left(\Phi_{\mathrm{m}}=-6.3 \mathrm{eV}\right), \mathrm{CuO}\left(\Phi_{\mathrm{m}}=-5.9 \mathrm{eV}\right)$ or $\mathrm{MoO}_{2}\left(\Phi_{\mathrm{m}}=-5.9 \mathrm{eV}\right) .85,86$ We have found that the highest 


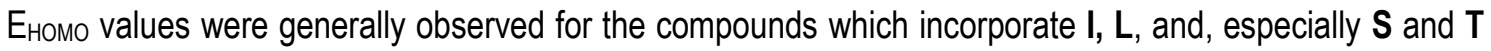
substituents in Y-position, where energy values $\mathrm{E}_{\text {номо }} \geq-4.9 \mathrm{eV}$ were obtained for all the I, $\mathbf{S}$ and $\mathbf{T}$ derivatives, along with the compounds $1 \mathrm{~L}$ and $\mathbf{5 L}$, being $5 \mathrm{~S}$ the compound with highest $\mathrm{E}_{\text {номо }}\left(\mathrm{E}_{\text {номо }}=-4.28\right.$ $\mathrm{eV})$. On the other hand, the lower energy values for the HOMO orbital have been obtained for compounds with s-tetrazine in X-position, which range from $-4.5 \mathrm{eV}$ (for 3S) to $-6.9 \mathrm{eV}$ (for 3P). These values are similar to some halogenated ethynylene-s-tetrazine derivatives studied previously, with $E_{\text {номо values in the }-6.22}$ $\mathrm{eV}$ to $-7.12 \mathrm{eV}$ range..$^{21}$

Despite the fact that ITO and Au electrodes are typically employed in ambipolar devices, the HOMO and LUMO energy values are not sufficiently well-balanced for both electron and hole charge injection, with the majority of the studied molecules herein. A more optimal charge injection would be obtained with a

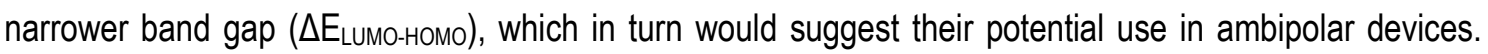
However, the calculated $\Delta \mathrm{E}_{\text {Lumo-Homo }}$ does not seem to guarantee that both ohmic hole and electron injection could be produced with the same electrode. Only in the case of compounds with $\mathbf{S}$ and $\mathbf{T}$ moieties in $\mathrm{Y}$ positions, with $\Delta \mathrm{E}_{\text {LUмо-номо }} \leq 2.0 \mathrm{eV}$ (see Table 1), it is possible to predict a certain ambipolar character.

Interestingly, the shapes of LUMOs showed in Figures 2 and S1 suggest that symmetry-broken effects could occur in the anionic state of some compounds such as the combinations of $\mathbf{1}$ and $\mathbf{5}$ rings with $\mathbf{P}, \mathbf{S}$ and $\mathbf{T}$ substituents. Some of them could be mixed-valence compounds, containing two redox centers in different oxidation states. Nevertheless, this effect could not be observed due to an overestimation of the charge delocalization in B3LYP calculations. ${ }^{87,88}$ For this reason, the anionic state of a model compound (1S) was investigated combining the hybrid functionals B3LYP (20\% HF exchange) and M06-2X (54\% HF exchange), and the HF method. Figure 3 shows the symmetry-broken geometry calculated for $1 \mathrm{~S}$ at the $\mathrm{HF} / 6-31+\mathrm{G}^{*}$ level in which the charge excess is localized in a part of the molecule. On the contrary, a-SOMO (single occupied molecular orbital) is spread out over both sides of the molecule in the geometries calculated with DFT functionals (please, consult the references $[87,88]$ for a more detailed study on this effect). The symmetry-broken effect were not observed for the cationic state of $1 \mathrm{~S}$.

LUMO

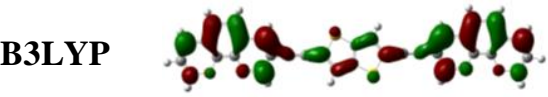

M06-2X

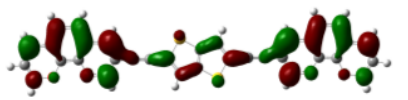

a-SOMO
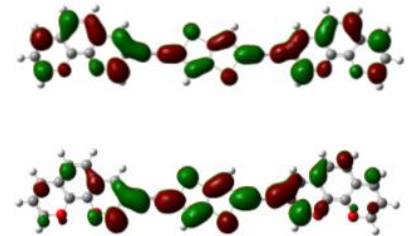

ß-SOMO

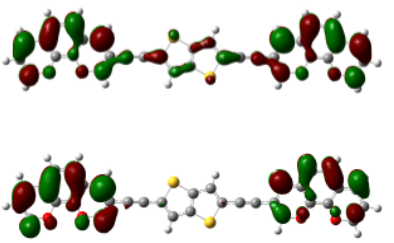




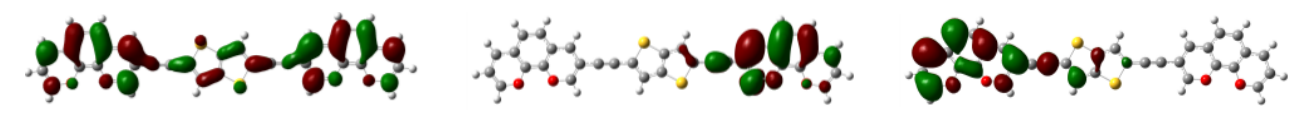

Figure 3. Isocontour plots ( $0.02 \mathrm{au})$ of LUMO and SOMO orbitals calculated for compound $1 \mathrm{~S}$ in neutral and anionic sates at the B3LYP/6-31+G*,$M 06-2 X / 6-31+G^{*}$ and $H F / 6-31+G^{*}$ levels of theory. 
Table 1. Energy values for $\mathrm{HOMO}$ and $\mathrm{LUMO}$ orbitals and their difference $\triangle \mathrm{E}_{\mathrm{Lumo-Homo}}$ (in eV) for all the studied compounds, calculated at B3LYP/6-31+G* level.

\begin{tabular}{|c|c|c|c|c|c|c|c|c|c|c|c|c|c|c|c|c|c|c|c|}
\hline & $\begin{array}{c}\text { Еномо } \\
\text { / eV }\end{array}$ & $\begin{array}{l}\text { Elumo } \\
\text { / eV }\end{array}$ & $\begin{array}{c}\Delta \text { ELUMO- }_{\text {HOMO }} \\
\text { eV }\end{array}$ & & $\begin{array}{c}\text { Еномо } \\
\text { / eV }\end{array}$ & $\begin{array}{c}\text { ELUMO } \\
\text { / eV }\end{array}$ & $\begin{array}{c}\Delta \text { ELUMO- } \\
\text { HOMO / } \\
\mathrm{eV}\end{array}$ & & $\begin{array}{c}\mathrm{E}_{\text {номо }} \\
\mathrm{leV}\end{array}$ & $\begin{array}{l}\text { ELumo } \\
\text { / eV }\end{array}$ & $\begin{array}{c}\Delta \text { ELUMO- } \\
\text { HOMO / } \\
\text { eV }\end{array}$ & & $\begin{array}{c}\text { Еномо } \\
/ \mathrm{eV}\end{array}$ & $\begin{array}{l}\text { Elumo } \\
\text { / eV }\end{array}$ & $\begin{array}{c}\Delta \text { ELUMO- }_{\text {LOMO }} \\
\text { eV }\end{array}$ & & $\begin{array}{c}\text { Еномо } \\
\text { / eV }\end{array}$ & $\begin{array}{l}\text { ELUMo } \\
\text { / eV }\end{array}$ & $\begin{array}{c}\Delta \text { ELUMO- } \\
\text { HOMO / } \\
\text { eV }\end{array}$ \\
\hline $1 \mathrm{~A}$ & -5.056 & -2.011 & 3.046 & $2 \mathrm{~A}$ & -5.394 & -2.401 & 2.992 & $3 A$ & -5.830 & -2.780 & 3.050 & $4 \mathrm{~A}$ & -5.472 & -2.259 & 3.212 & $5 \mathrm{~A}$ & -5.195 & -1.755 & 3.440 \\
\hline $1 \mathrm{~B}$ & -5.348 & -2.293 & 3.055 & $2 \mathrm{~B}$ & -5.710 & -2.691 & 3.020 & $3 B$ & -6.247 & -2.991 & 3.256 & $4 \mathrm{~B}$ & -5.850 & -2.567 & 3.283 & $5 B$ & -5.539 & -2.081 & 3.457 \\
\hline $1 \mathrm{C}$ & -5.363 & -2.368 & 2.995 & $2 \mathrm{C}$ & -5.722 & -2.737 & 2.985 & $3 C$ & -6.276 & -3.011 & 3.265 & $4 C$ & -5.880 & -2.618 & 3.263 & $5 \mathrm{C}$ & -5.574 & -2.185 & 3.388 \\
\hline $2 \mathrm{D}$ & -5.260 & -2.291 & 2.968 & $2 \mathrm{D}$ & -5.571 & -2.623 & 2.948 & $3 D$ & -5.975 & -2.862 & 3.113 & $4 \mathrm{D}$ & -5.687 & -2.505 & 3.181 & $5 D$ & -5.441 & -2.120 & 3.320 \\
\hline $1 \mathrm{E}$ & -5.233 & -2.247 & 2.986 & $2 \mathrm{E}$ & -5.542 & -2.580 & 2.962 & $3 E$ & -5.944 & -2.820 & 3.124 & $4 \mathrm{E}$ & -5.655 & -2.459 & 3.196 & $5 E$ & -5.412 & -2.070 & 3.342 \\
\hline $1 \mathrm{~F}$ & -5.401 & -2.416 & 2.986 & $2 \mathrm{~F}$ & -5.727 & -2.746 & 2.981 & $3 F$ & -6.185 & -2.995 & 3.189 & $4 \mathrm{~F}$ & -5.874 & -2.639 & 3.235 & $5 F$ & -5.610 & -2.259 & 3.352 \\
\hline $1 G$ & -5.420 & -2.429 & 2.991 & $2 G$ & -5.744 & -2.755 & 2.989 & $3 G$ & -6.208 & -3.005 & 3.203 & $4 G$ & -5.898 & -2.651 & 3.247 & $5 G$ & -5.634 & -2.273 & 3.361 \\
\hline $1 \mathrm{H}$ & -5.120 & -2.664 & 2.456 & $2 \mathrm{H}$ & -5.343 & -2.909 & 2.434 & $3 \mathrm{H}$ & -5.564 & -3.095 & 2.469 & $4 \mathrm{H}$ & -5.374 & -2.825 & 2.549 & $5 \mathrm{H}$ & -5.216 & -2.571 & 2.645 \\
\hline 11 & -4.930 & -1.935 & 2.994 & 21 & -4.827 & -1.966 & 2.861 & 31 & -4.963 & -2.550 & 2.412 & 41 & -4.784 & -1.819 & 2.965 & 51 & -4.529 & -1.360 & 3.169 \\
\hline $1 \mathrm{~J}$ & -5.332 & -2.132 & 3.200 & $2 \mathrm{~J}$ & -5.113 & -2.142 & 2.971 & $3 \mathrm{~J}$ & -5.367 & -2.771 & 2.596 & $4 \mathrm{~J}$ & -5.126 & -2.028 & 3.098 & $5 \mathrm{~J}$ & -4.939 & -1.547 & 3.391 \\
\hline $1 \mathrm{~K}$ & -5.561 & -2.061 & 3.500 & $2 \mathrm{~K}$ & -5.324 & -2.148 & 3.176 & $3 K$ & -5.573 & -2.758 & 2.815 & $4 \mathrm{~K}$ & -5.334 & -1.992 & 3.342 & $5 K$ & -5.107 & -1.464 & 3.643 \\
\hline $1 \mathrm{~L}$ & -4.868 & -2.217 & 2.652 & $2 \mathrm{~L}$ & -5.074 & -2.553 & 2.522 & $3 \mathrm{~L}$ & -5.231 & -2.784 & 2.447 & $4 \mathrm{~L}$ & -5.058 & -2.437 & 2.621 & $5 \mathrm{~L}$ & -4.907 & -2.022 & 2.884 \\
\hline $1 \mathrm{M}$ & -5.343 & -2.572 & 2.771 & $2 \mathrm{M}$ & -5.613 & -2.907 & 2.706 & $3 \mathrm{M}$ & -5.927 & -3.171 & 2.756 & $4 \mathrm{M}$ & -5.680 & -2.810 & 2.870 & $5 \mathrm{M}$ & -5.474 & -2.415 & 3.058 \\
\hline $1 \mathrm{~N}$ & -5.361 & -2.603 & 2.759 & $2 \mathrm{~N}$ & -5.619 & -2.916 & 2.704 & $3 \mathrm{~N}$ & -5.882 & -3.162 & 2.720 & $4 \mathrm{~N}$ & -5.679 & -2.823 & 2.857 & $5 \mathrm{~N}$ & -5.495 & -2.464 & 3.031 \\
\hline 10 & -5.154 & -2.484 & 2.670 & 20 & -5.355 & -2.789 & 2.566 & 30 & -5.502 & -3.022 & 2.480 & 40 & -5.356 & -2.691 & 2.665 & 50 & -5.219 & -2.342 & 2.877 \\
\hline $1 \mathrm{P}$ & -5.931 & -3.711 & 2.220 & $2 \mathrm{P}$ & -6.263 & -3.856 & 2.407 & $3 P$ & -6.863 & -3.993 & 2.870 & $4 \mathrm{P}$ & -6.493 & -3.827 & 2.666 & $5 P$ & -6.203 & -3.697 & 2.506 \\
\hline $1 Q^{a}$ & -5.394 & -2.366 & 3.028 & $2 Q$ & -5.725 & -2.701 & 3.024 & $3 Q$ & -6.193 & -2.949 & 3.244 & $4 Q$ & -5.875 & -2.585 & 3.291 & $5 Q$ & -5.611 & -2.202 & 3.410 \\
\hline $1 \mathrm{R}$ & -5.653 & -2.645 & 3.008 & $2 \mathrm{R}$ & -6.005 & -2.962 & 3.043 & $3 R$ & -6.603 & -3.227 & 3.376 & $4 \mathrm{R}$ & -6.227 & -2.869 & 3.358 & $5 R$ & -5.926 & -2.515 & 3.411 \\
\hline $1 S$ & -4.307 & -2.303 & 2.004 & $2 S$ & -4.446 & -2.473 & 1.974 & $3 S$ & -4.518 & -2.669 & 1.849 & $4 S$ & -4.388 & -2.383 & 2.005 & $5 S$ & -4.280 & -2.253 & 2.027 \\
\hline $1 \mathrm{~T}$ & -4.501 & -2.492 & 2.009 & $2 \mathrm{~T}$ & -4.621 & -2.692 & 1.929 & $3 \mathrm{~T}$ & -4.687 & -2.894 & 1.793 & $4 \mathrm{~T}$ & -4.575 & -2.605 & 1.970 & $5 T$ & -4.480 & -2.442 & 2.038 \\
\hline
\end{tabular}


We analyze now EA (the energy released when one electron is added to the system in the gaseous state) and IP (the energy released when one electron is removed to the system in gaseous state) descriptors for the charge injection efficiency. Table 2 collects both, adiabatic and vertical, EAs and IPs obtained for some chosen compounds (the complete set of values in shown in Table S1 of ESI). We must remark that in order to efficiently inject an electron into the LUMO orbital, the EA must be high enough to ensure the efficient charge injection and improve the environmental stability of the material; while IP must be low enough to allow an efficient hole injection into the HOMO orbital. Taking into account that the difference between the vertical and adiabatic values is small, this result indicates that the relaxation upon charge injection is too small. Studying the EA values as a function of substituents in Y-positions, the compounds incorporating the substituent $\mathbf{P}$ in this position generally showed highlighted values of $E A$, in consistency with the calculated ELumo values. For instance, the AEAs estimated for $2 \mathbf{P}, 4 \mathbf{P}$ and, especially, 3P are within the $3.0-4.0 \mathrm{eV}$ range proposed by Newman et al. for $n$-type organic semiconductors. ${ }^{35}$ Taking into account the central moiety, i.e. the ring in X-position, we have observed that the compounds with s-tetrazine (compounds 3 ) in their formulations show the highest values of EAs. On the other hand, the lowest AIP values ( $\leq 5.5 \mathrm{eV}$ ) have been calculated for 2,9-dihydropyrano[3,2-h]chromene (S) and 2,9dihydrothiopyrano[3,2-h]thiochromene $(\mathrm{T})$ derivatives as well as for the compound 1I. Regarding the substituent in Y-position, the lowest AIPs were normally obtained for the compounds which having a thieno[3,2-b]thiophene (1) ring, more precisely the $1 S$.

Once the values of $\mathrm{E}_{\text {Luмо }}\left(\mathrm{E}_{\text {номо }}\right.$ ) and AEA (AIP) were analyzed in great detail, we can conclude that the most favorable electron (hole) charge injection could be expected for the compounds with $\mathbf{P}(\mathbf{I}, \mathbf{S}$ and T) moiety (moieties) in its (their) structure(s), being 3P (1S) the most favorable. However, a favorable electron injection cannot be discarded for some compounds having a s-tetrazine ring in X-position such as $3 M / 3 N / 3 R$ and, again, $3 P$.

Charge Transport Properties. As previously stated, the charge mobility depends on two key properties, i.e. the reorganization energy and the electronic coupling. Table 2 gathers also the internal reorganization energies $\left(\lambda_{i}\right)$ values for the studied compounds, for which one of the reorganization energy (electron or hole) satisfy the imposed condition of $\lambda_{i} \leq 0.15 \mathrm{eV}$ (all values are collected in Table S1). The set of compounds satisfying this condition $\left(\lambda_{i}^{-} \leq 0.15 \mathrm{eV}\right)$ for electron transport generally include substituents $\mathbf{H}, \mathbf{P}$ and $\mathbf{T}$ moieties in Y-position, obtaining the lowest for $\mathbf{T}$ fragment in $\mathbf{1}$ and $\mathbf{5}$ compounds, which central bodies are thieno[3,2-b]thiophene and benzene rings, respectively. Generally speaking, the presence of nitrogen atoms in the substituents of Y-position seems to have a negative effect on the reorganization energies, increasing them, i.e. I, $\mathbf{J}$ and $\mathbf{K}$ moieties in Y-position; while the absence of heteroatoms or the presence of atoms with low electronegativity such as sulfur atoms in $Y$-positions yield the lowest values for reorganization energy. In that sense, low $\lambda_{i}^{-}$values $(\leq 0.15 \mathrm{eV})$ were calculated for the compounds $1 \mathrm{H}, 1 \mathrm{P}, 1 \mathrm{~T}, 2 \mathrm{P}, 3 \mathrm{H}, 4 \mathrm{H}, 4 \mathrm{~T}$, $5 \mathrm{H}, 5 \mathrm{P}, 5 \mathrm{~S}$ and $\mathbf{5 T}$, where $1 \mathrm{~T}$ and $\mathbf{5 T}$ stand out among the rest, with values of $\lambda_{i}^{-}=0.12$ and $0.11 \mathrm{eV}$, respectively. These energies are lower than those reported for typical aromatic compounds investigated as 
$n$-type semiconductors such as pentacene and perfluoropentacene $(0.24$ and $0.13 \mathrm{eV}$, respectively, calculated at the B3LYP/6-31+G* level), ${ }^{36}$ arene diimides $(0.22-0.35 \mathrm{eV}$, calculated at the B3LYP/6$31++G^{* *}$ level), ${ }^{53}$ fluoroarene-oligothiophenes $\left(0.22-0.34 \mathrm{eV}\right.$, calculated at the B3LYP/6-31G* level), ${ }^{89}$ rubrenes $\left(0.17-0.42 \mathrm{eV} \text {, calculated at the B3LYP/6-311 } \mathrm{G}^{\star \star} \text { level }\right)^{90}$ and most recently some rubicene or rubicene derivatives $\left(0.12-0.31 \mathrm{eV} \text {, calculated at the } B 3 L Y P / 6-31+G^{*} \text { level) }\right)^{46}$ or some novel cycloparaphenylenes $\left(0.23-0.38 \mathrm{eV}\right.$, calculated at the B3LYP/6-31+G* level). ${ }^{91}$ The values calculated for $\lambda_{i}^{+}$are in general smaller than their counterparts, i.e. $\lambda_{i}^{-}$. For instance, values of $\lambda_{i}^{+} \leq 0.10 \mathrm{eV}$ were calculated for the compounds $3 \mathrm{H}, 3 \mathrm{~J}, 4 \mathrm{~J}$ and $5 \mathrm{I}$, with $1 \mathrm{~T}, 2 \mathrm{~T}, 3 \mathrm{~N}, 3 \mathrm{~T}, 4 \mathrm{H}, 4 \mathrm{~T}, 5 \mathrm{H}$ and $5 \mathrm{~T}$ displaying also close results. In general, in the case of hole transport, the lowest values were obtained for $\mathrm{H}, \mathrm{J}, \mathrm{T}$ moieties in Y-position, and exceptionally for $\mathbf{5 l}$. It should be highlighted the particularly low reorganization energies computed for $3 \mathrm{H} / 3 \mathrm{~J}$ and $4 \mathrm{~J}(\leq 0.09 \mathrm{eV})$. These energies are comparable to those reported for common $p$-type semiconductors such as pentacene $\left(0.090 \mathrm{eV}\right.$, calculated at the B3LYP/6-31++G** level), ${ }^{36}$ some tetrathiofulvenes $(0.071-0.234 \mathrm{eV} \text {, calculated at the B3LYP/6-31G** level })^{92}$, oligoacenes and oligothiopenes $\left(0.077-0.182 \mathrm{eV} \text {, calculated at the B3LYP/6-31G } \mathrm{G}^{* *} \text { level) }\right)^{93}$ and dibenzo-thieno-dithiophene $\left(0.096 \mathrm{eV}\right.$, calculated at the B3LYP/6-31+G* level) ${ }^{94}$ It must also be highlighted that some compounds show low and balanced $\lambda_{i}^{-}$and $\lambda_{i}^{+}$values. For instance, in the case of that both reorganization energies are $\leq 0.16$ $\mathrm{eV}$ and $\left|\lambda_{i}^{-}-\lambda_{i}^{+}\right| \leq 0.03 \mathrm{eV}$. These conditions are obtained for $\mathbf{1 H} / \mathbf{1 T}, \mathbf{2 H} / \mathbf{2 T}, \mathbf{5 H} / \mathbf{5 S} / \mathbf{5 T}$. Compounds $1 \mathrm{~T}$ and $\mathbf{5 T}$ show particularly low and balanced reorganization energies $\left(\lambda_{i} \leq 0.12 \mathrm{eV}\right.$ and $\left.\left|\lambda_{i}^{-}-\lambda_{i}^{+}\right| \leq 0.01 \mathrm{eV}\right)$.

As a general summary (see Table S1 in ESI), the presence of non-fused rings in the Y-position (such as pyrrole, furan or thiophene) yields high values of reorganization energies, independently of the nature of the central rings. Studying the evolution of reorganization energy as a function of connected rings in Y-position, the carbazole derivatives yield reorganization energy values close to $0.2 \mathrm{eV}$ for both hole and electron charge carriers. However, the highest values for electron reorganization energies have been obtained for anthracene derivatives, with $\lambda_{i} \geq 0.8 \mathrm{eV}$, except for $\mathbf{H}$ moiety in $\mathrm{Y}$-position. This fact is related to the somewhat localized character of LUMOs on the central rings, despite the large number of fused rings of the anthracene derivatives (see Figure S1). Regarding the central ring, we have observed that $\lambda_{i} \leq 0.2$ $\mathrm{eV}$ has been mostly obtained for non-fused rings, i.e. s-tetrazine (compounds 3 ), pyrazine (compounds 4) and benzene (compounds 5 ), as central rings. We have noted that the introduction of ethynylene moiety in $s$-tetrazine derivatives reduces significantly the values of $\lambda_{i}^{-}$, especially for furan or thiophene rings; however, for hole transport, this reduction is not significant. ${ }^{21}$ 
Table 2. Calculated lonization Potential (AIP and VIP), Electron Affinity (AEA and VEA), and Reorganization Energy $\left(\lambda_{i}^{+}\right.$and $\lambda_{i}$ ) values for some selected compounds after the screening performed, where the reorganization energy is low or equal to $0.15 \mathrm{eV}$. All the parameters have been calculated at the B3LYP/6$31+G^{*}$ level.

\begin{tabular}{|c|c|c|c|c|c|c|}
\hline \multirow{2}{*}{ Compounds } & \multicolumn{3}{|c|}{ Holes } & \multicolumn{3}{|c|}{ Electrons } \\
\hline & AIP (eV) & $\mathrm{VIP}(\mathrm{eV})$ & $\lambda_{\mathrm{i}}^{+}(\mathrm{eV})$ & $\mathrm{AEA}(\mathrm{eV})$ & VEA $(e V)$ & $\lambda_{i}(\mathrm{eV})$ \\
\hline $1 \mathrm{H}$ & 5.986 & 6.058 & 0.148 & 1.820 & 1.748 & 0.149 \\
\hline $1 \mathrm{P}$ & 6.843 & 6.957 & 0.230 & 2.886 & 2.812 & 0.148 \\
\hline $1 \mathrm{~S}$ & 5.150 & 5.209 & 0.119 & 1.536 & 1.459 & 0.172 \\
\hline $1 \mathrm{~T}$ & 5.319 & 5.370 & 0.106 & 1.733 & 1.677 & 0.116 \\
\hline $2 \mathrm{H}$ & 6.208 & 6.279 & 0.150 & 2.047 & 1.974 & 0.159 \\
\hline $2 \mathrm{~J}$ & 6.025 & 6.094 & 0.147 & 1.492 & 1.055 & 1.022 \\
\hline 20 & 6.174 & 6.246 & 0.148 & 1.944 & 1.834 & 0.223 \\
\hline $2 \mathrm{P}$ & 7.165 & 7.296 & 0.268 & 3.033 & 2.956 & 0.154 \\
\hline $2 S$ & 5.298 & 5.357 & 0.124 & 1.739 & 1.634 & 0.252 \\
\hline $2 \mathrm{~T}$ & 5.442 & 5.498 & 0.111 & 1.933 & 1.858 & 0.162 \\
\hline 3D & 6.876 & 6.947 & 0.146 & 1.863 & 1.772 & 0.181 \\
\hline $3 E$ & 6.844 & 6.918 & 0.152 & 1.821 & 1.728 & 0.186 \\
\hline $3 \mathrm{~F}$ & 7.100 & 7.174 & 0.151 & 1.997 & 1.902 & 0.190 \\
\hline $3 G$ & 7.104 & 7.178 & 0.153 & 2.021 & 1.926 & 0.188 \\
\hline $3 \mathrm{H}$ & 6.491 & 6.534 & 0.088 & 2.157 & 2.088 & 0.137 \\
\hline $3 \mathrm{~J}$ & 6.339 & 6.374 & 0.071 & 1.662 & 1.268 & 0.793 \\
\hline $3 \mathrm{~L}$ & 6.151 & 6.209 & 0.122 & 1.783 & 1.693 & 0.179 \\
\hline $3 \mathrm{~N}$ & 6.776 & 6.830 & 0.113 & 2.205 & 2.113 & 0.187 \\
\hline 30 & 6.377 & 6.439 & 0.125 & 2.085 & 1.986 & 0.199 \\
\hline $3 Q$ & 7.087 & 7.155 & 0.139 & 1.963 & 1.869 & 0.189 \\
\hline $3 S$ & 5.405 & 5.476 & 0.126 & 1.849 & 1.719 & 0.259 \\
\hline $3 T$ & 5.542 & 5.598 & 0.111 & 2.051 & 1.965 & 0.180 \\
\hline $4 \mathrm{H}$ & 6.291 & 6.313 & 0.107 & 1.919 & 1.846 & 0.146 \\
\hline $4 \mathrm{~J}$ & 6.094 & 6.136 & 0.086 & 1.159 & 0.864 & 0.995 \\
\hline $4 \mathrm{~L}$ & 5.964 & 6.030 & 0.138 & 1.463 & 1.365 & 0.195 \\
\hline $4 \mathrm{~N}$ & 6.557 & 6.625 & 0.142 & 1.907 & 1.805 & 0.205 \\
\hline 40 & 6.218 & 6.284 & 0.132 & 1.797 & 1.690 & 0.218 \\
\hline $4 S$ & 5.272 & 5.335 & 0.124 & 1.609 & 1.509 & 0.228 \\
\hline $4 \mathrm{~T}$ & 5.427 & 5.482 & 0.110 & 1.913 & 1.745 & 0.144 \\
\hline $5 \mathrm{H}$ & 6.130 & 6.186 & 0.114 & 1.684 & 1.619 & 0.134 \\
\hline 51 & 5.474 & 5.514 & 0.082 & 0.379 & 0.321 & 0.160 \\
\hline $5 \mathrm{~L}$ & 5.802 & 5.875 & 0.149 & 1.093 & 0.995 & 0.197 \\
\hline $5 \mathrm{~N}$ & 6.371 & 6.445 & 0.152 & 1.589 & 1.489 & 0.203 \\
\hline 50 & 6.074 & 6.142 & 0.137 & 1.431 & 1.386 & 0.217 \\
\hline $5 P$ & 7.154 & 7.260 & 0.218 & 2.839 & 2.763 & 0.153 \\
\hline $5 S$ & 5.161 & 5.221 & 0.120 & 1.430 & 1.363 & 0.141 \\
\hline $5 \mathrm{~T}$ & 5.329 & 5.382 & 0.107 & 1.643 & 1.587 & 0.111 \\
\hline
\end{tabular}

The electronic coupling is the second key parameter to be calculated. It strongly depends on the electronic interactions between neighboring molecules and, in turn, on the relative solid-state spatial arrangement. As previously stated, the binding energy $\left(E_{b}\right)$ - defined as the energy difference between the dimer and the isolated molecules_- was calculated for different stacking dimers and plotted as a function of the relative $(x, y)$-displacement between both molecules. Then, the charge transfer integrals were computed for the arrangements with the lowest binding energy. Again, it should be noted that the exploration of the energy landscapes was performed for a set of compounds displaying low reorganization energies (i.e. the threshold value was established as $\lambda_{i} \leq 0.15 \mathrm{eV}$ ). Figure 4 shows the results obtained in the calculations of 
$E_{b}$ for some studied compounds (Figure S2 collects the landscape for all the studied compounds), while Table 3 gathers the binding energy ( $\mathrm{E}_{\mathrm{b}}$, in $\mathrm{eV}$ ) for all the studied compounds. It is noteworthy that the lowest binding energy values are observed slightly displaced from a perfectly cofacial disposition, i.e., $x=y=0 \AA$, suggesting that the interplay between attractive and repulsive non-covalent interactions dominate the binding energy landscape in the region. For the selected compounds, a broad minimum mostly appears for $\mathrm{x}$ - and $\mathrm{y}$-displacements lower than $3 \AA$, expect for $3 \mathrm{~T}$, in which appears at $\mathrm{x}=4 \AA$, being the most common position $x=y=1 \AA$ and yielding values for binding energies ranging from -0.84 to $-1.28 \mathrm{eV}$.

a)

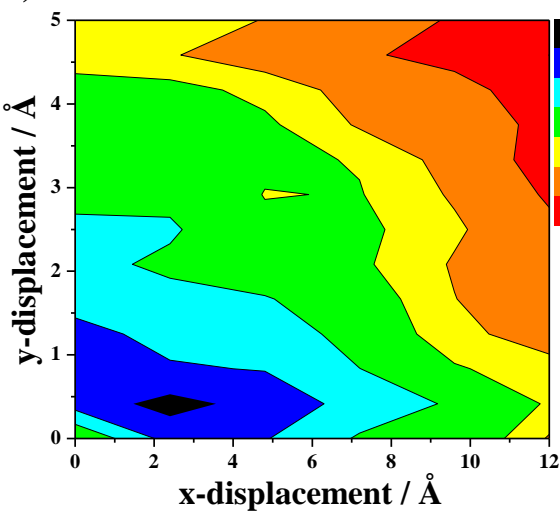

c)
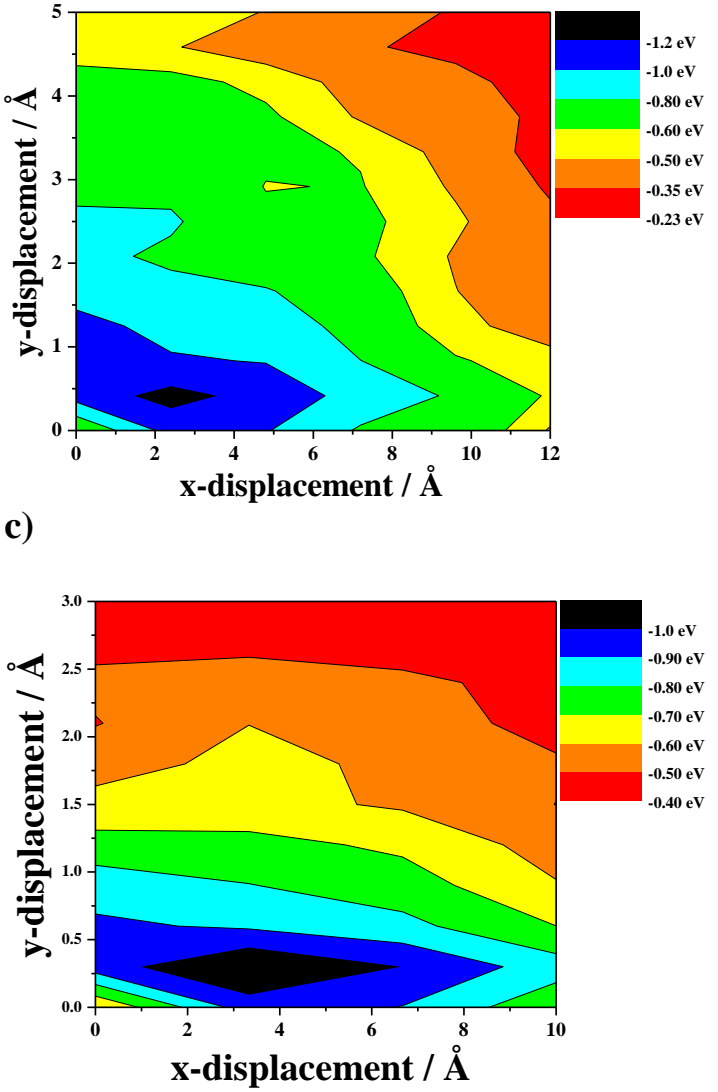

b)

d)

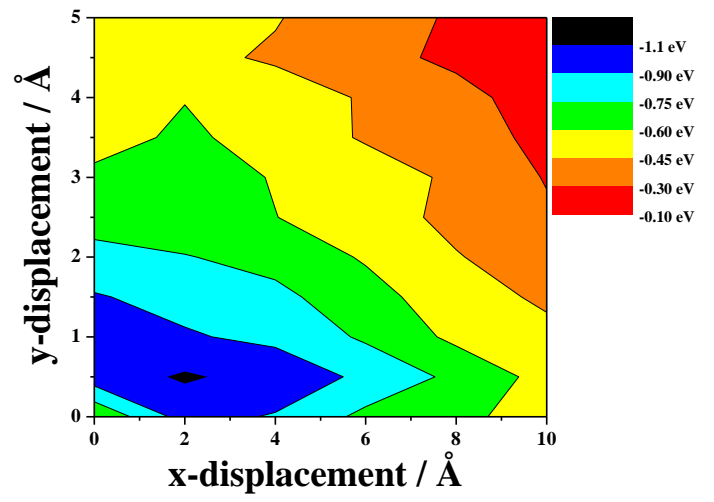

e)

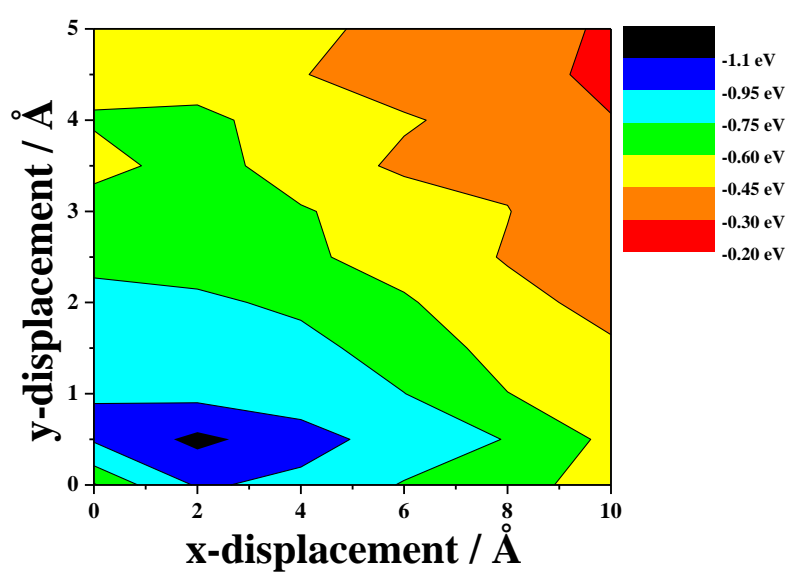


Figure 4. Binding energy values for a) $1 \mathrm{H}$; b) $2 \mathrm{H}$; c) $3 \mathrm{H}$; d) $4 \mathrm{H}$ and e) $5 \mathrm{H}$ dimers as a function of the relative $(x, y)$-displacement between both interacting molecules, keeping fixed $z=3.5 \AA$

Table 3 also shows the calculated $t_{12}$ values for the arrangements with the lowest binding energies, for both hole and electron charge carriers, with results ranging from 9 to $149 \mathrm{meV}$ (12 to $149 \mathrm{meV}$ ) for holes (electrons). In both cases, and due to their large range, the obtained values are close to the some previous estimates for hole transfer such as dimethylquaterthiophene $(20 \mathrm{meV}$, calculated at the B3LYP/6-31G* level), ${ }^{95}$ tetrafluootetracyanoquinodimethane derivatives $\left(28-41 \mathrm{meV}\right.$, at the B3LYP/6-31G* level), ${ }^{95}$ antharacenepyromellitic dianhydride $\left(-128 \mathrm{meV}\right.$, at the B3LYP/6-31G* level), ${ }^{95}$ quaterthiophene and sexithiophene (from 0.68 to $39.95 \mathrm{meV}$ and 0.38 to $36 \mathrm{meV}$, respectively, at the PW91/6-31G* level), ${ }^{96}$ pentacene derivatives with the trialkylsilylethynyl groups (from 1.48 to $82.13 \mathrm{meV}$, at the PW91/TZ2P level) ${ }^{97}$ or perfluoroarene-modified oligothiophenes (26 - $53 \mathrm{meV}$, at the PW91/TZP level) ${ }^{89}$ in the case of hole $t_{12}$; while the obtained values for electron transfer are similar to those calculated for pentacene (131 $\mathrm{meV}$ at the B3LYP/TVP level) $)^{51}$ and for pentacene trialkylsilylethynyl derivatives (with values ranging from $1.27 \mathrm{meV}$ to $128.83 \mathrm{meV}$, at the PW91/TZ2P level), ${ }^{97}$ for dimethylquaterthiophene (65 meV, at the B3LYP/6$31 \mathrm{G}^{*}$ level), ${ }^{97}$ for tetrafluorotetracyanoquinodimethane derivatives $(72-75 \mathrm{meV}$, at the B3LYP/6-31G* level), ${ }^{97}$ for antharacenepyromellitic dianhydride (86 meV, at the B3LYP/6-31G* level), ${ }^{97}$ for perfluoroarenemodified oligothiophenes ( $13-62 \mathrm{meV}$, at the PW91/TZP level), 89 for the perylene derivatives $(26-64$ $\mathrm{meV}$, at the PW91PW91/6-31G* level), ${ }^{98}$ and for diimides derivatives studied by Chen et al. (21.6 - 87.5 $\mathrm{meV}$, at the PW91PW91/6-31G* level) ${ }^{53}$ and by Di Donato et al. (74 - $96 \mathrm{meV}$, calculated at the B3LYP/3$21 \mathrm{G}$ level). ${ }^{99}$

Table 3. Lowest Binding Energies $\left(E_{b}\right)$ and the corresponding relative $(x, y)$-positions of the molecules within stacked dimers of the studied compounds, together with the charge integral transfer $\left(t_{12}\right)$ and their corresponding charge transfer rate $\left(\mathrm{k}_{\mathrm{CT}}\right)$ for both hole and electron.

\begin{tabular}{|c|c|c|c|c|c|c|c|}
\hline & \multirow{2}{*}{ (x.y) Coordinantes / $\AA$} & \multirow{2}{*}{$E_{b} / e V$} & \multicolumn{2}{|c|}{ Hole } & \multicolumn{2}{|c|}{ Electrons } & \multirow[b]{2}{*}{$\mathrm{k}_{C} \mathrm{~T}^{\mathrm{rel}-}$} \\
\hline & & & $\mathrm{t}_{12} / \mathrm{meV}$ & $\mathrm{k}_{\mathrm{CT}} / \mathrm{s}^{-1}$ & $\mathrm{t}_{12} / \mathrm{meV}$ & $\mathrm{k}_{\mathrm{CT}} / \mathrm{s}^{-1}$ & \\
\hline $1 \mathrm{H}$ & $(1,1)$ & -1.28 & 92 & $8.09 \times 10^{13}$ & 43 & $1.78 \times 10^{13}$ & 4.54 \\
\hline $1 \mathrm{P}$ & $(3,0)$ & -1.28 & 132 & $1.67 \times 10^{14}$ & 66 & $2.78 \times 10^{13}$ & 6.01 \\
\hline $1 S$ & $(1,1)$ & -1.17 & 60 & $3.07 \times 10^{13}$ & 61 & $4.13 \times 10^{13}$ & 0.74 \\
\hline $1 \mathrm{~T}$ & $(1,1)$ & -1.36 & 84 & $7.57 \times 10^{13}$ & 50 & $2.96 \times 10^{13}$ & 2.56 \\
\hline $2 \mathrm{H}$ & $(1,1)$ & -1.20 & 52 & $2.46 \times 10^{13}$ & 49 & $2.28 \times 10^{13}$ & 1.08 \\
\hline $2 \mathrm{~J}$ & $(1,1)$ & -1.20 & 38 & $1.76 \times 10^{11}$ & 31 & $9.28 \times 10^{12}$ & 0.02 \\
\hline 20 & $(3,0)$ & -1.28 & 111 & $8.56 \times 10^{13}$ & 82 & $6.46 \times 10^{13}$ & 1.33 \\
\hline $2 \mathrm{P}$ & $(3,-1)$ & -1.28 & 54 & $2.72 \times 10^{13}$ & 48 & $1.26 \times 10^{13}$ & 2.16 \\
\hline $2 S$ & $(3,1)$ & -1.20 & 22 & $2.77 \times 10^{12}$ & 12 & $1.56 \times 10^{12}$ & 1.78 \\
\hline $2 T$ & $(0,2)$ & -1.36 & 9 & $7.26 \times 10^{11}$ & 149 & $2.57 \times 10^{14}$ & 0.00 \\
\hline $3 \mathrm{D}$ & $(3,0)$ & -0.98 & 13 & $1.37 \times 10^{12}$ & 59 & $3.34 \times 10^{13}$ & 0.04 \\
\hline $3 \mathrm{E}$ & $(3,0)$ & -0.90 & 13 & $1.34 \times 10^{12}$ & 58 & $3.17 \times 10^{13}$ & 0.04 \\
\hline $3 F$ & $(3,0)$ & -0.95 & 15 & $1.75 \times 10^{12}$ & 57 & $3.08 \times 10^{13}$ & 0.06 \\
\hline $3 G$ & $(3,0)$ & -1.09 & 13 & $1.33 \times 10^{12}$ & 58 & $3.15 \times 10^{13}$ & 0.04 \\
\hline $3 \mathrm{H}$ & $(1,1)$ & -1.12 & 14 & $1.99 \times 10^{12}$ & 35 & $2.37 \times 10^{13}$ & 0.08 \\
\hline $3 \mathrm{~J}$ & $(1,0)$ & -1.03 & 139 & $7.39 \times 10^{12}$ & 63 & $5.60 \times 10^{13}$ & 0.13 \\
\hline $3 \mathrm{~L}$ & $(1,1)$ & -0.87 & 12 & $1.18 \times 10^{12}$ & 38 & $1.58 \times 10^{13}$ & 0.07 \\
\hline $3 \mathrm{~N}$ & $(1,1)$ & -1.01 & 14 & $1.55 \times 10^{12}$ & 37 & $1.57 \times 10^{13}$ & 0.10 \\
\hline 30 & $(1,1)$ & -1.09 & 14 & $1.49 \times 10^{12}$ & 38 & $1.40 \times 10^{13}$ & 0.11 \\
\hline
\end{tabular}




$\begin{array}{llllllll}3 \mathrm{Q} & (0,3) & -1.09 & 13 & 1.32 \times 10^{12} & 58 & 3.38 \times 10^{13} & 0.04 \\ 3 \mathrm{X} & (2,0) & -1.06 & 12 & 7.95 \times 10^{11} & 57 & 3.49 \times 10^{13} & 0.02 \\ 3 \mathrm{~T} & (4,0) & -1.22 & 11 & 9.91 \times 10^{11} & 27 & 8.43 \times 10^{12} & 0.12 \\ 4 \mathrm{H} & (1,1) & -1.12 & 100 & 9.71 \times 10^{13} & 45 & 2.39 \times 10^{13} & 4.06 \\ 4 \mathrm{~J} & (1,1) & -1.09 & 47 & 3.08 \times 10^{11} & 30 & 1.18 \times 10^{13} & 0.03 \\ 4 \mathrm{~L} & (1,1) & -0.84 & 132 & 1.32 \times 10^{14} & 26 & 6.83 \times 10^{12} & 19.33 \\ 4 \mathrm{~N} & (1,1) & -1.06 & 149 & 1.60 \times 10^{14} & 28 & 7.76 \times 10^{12} & 20.62 \\ 4 \mathrm{O} & (3,0) & -1.14 & 115 & 8.96 \times 10^{13} & 66 & 4.53 \times 10^{13} & 1.98 \\ 4 \mathrm{~S} & (2,0) & -1.09 & 14 & 1.26 \times 10^{12} & 80 & 6.93 \times 10^{13} & 0.02 \\ 4 \mathrm{~T} & (1,1) & -1.25 & 98 & 9.41 \times 10^{13} & 58 & 3.91 \times 10^{13} & 2.41 \\ 5 \mathrm{H} & (1,1) & -1.14 & 88 & 7.98 \times 10^{13} & 39 & 1.73 \times 10^{13} & 4.61 \\ 5 \mathrm{I} & (1,1) & -1.06 & 48 & 2.09 \times 10^{13} & 61 & 4.97 \times 10^{13} & 0.42 \\ 5 \mathrm{~L} & (1,1) & -0.84 & 138 & 1.43 \times 10^{14} & 38 & 1.38 \times 10^{13} & 10.36 \\ 5 \mathrm{~N} & (1,1) & -1.06 & 140 & 1.43 \times 10^{14} & 38 & 1.36 \times 10^{13} & 10.51 \\ 5 \mathrm{O} & (1,1) & -1.17 & 54 & 1.99 \times 10^{13} & 42 & 1.79 \times 10^{13} & 1.11 \\ 5 \mathrm{P} & (1,1) & -1.14 & 58 & 3.15 \times 10^{13} & 44 & 1.31 \times 10^{13} & 2.40 \\ 5 \mathrm{~S} & (2,0) & -1.06 & 18 & 3.22 \times 10^{12} & 94 & 9.77 \times 10^{13} & 0.03 \\ 5 \mathrm{~T} & (1,1) & -1.22 & 90 & 9.37 \times 10^{13} & 68 & 5.45 \times 10^{13} & 1.72\end{array}$

After all the systematic screening performed, the calculated $\lambda_{i}$ and $t_{12}$ values can be consequently introduced in eq (1) to calculate the corresponding $\mathrm{k}_{\mathrm{CT}}$. Table 3 shows the values for both hole and electron $\mathrm{k}_{\mathrm{CT}}$, togheter with the $k_{C T}^{r e l}$, obtained from the ratio between both $\mathrm{k}_{\mathrm{CT}}$, i.e. $\mathrm{k}_{\mathrm{CT}^{+}} / \mathrm{k}_{\mathrm{CT}}$. It can be seen that the highest $\mathrm{k}_{\mathrm{C}}$ value for hole hopping was obtained for $1 \mathrm{P}$ while the counterpart for electron hopping corresponds to 2T. The most of the $\mathrm{k}_{\mathrm{CT}}$ values collected in the table lie within the range of $10^{12}$ to $10^{14} \mathrm{~s}^{-1}$, which are high in comparison to those calculated, through the MLJ formalism in previous works, for the main charge hopping pathyways in crystalline organic molecules such as 1,4-benzoquinone derivatives $\left(\mathrm{k}_{\mathrm{CT}}{ }^{-}=1\right.$ $-10 \times 10^{11} \mathrm{~s}^{-1}$, calculated at the B3LYP/6-31G* level), perylene bisimide derivatives $\left(\mathrm{k}_{\mathrm{CT}^{*}}=0.03-23 \times 10^{11}\right.$ $\mathrm{s}^{-1}$, calculated at the B3LYP/3-21G level), dibenzo-thieno-dithiophene $\left(\mathrm{k}_{\mathrm{CT}^{+}}=1-21 \times 10^{12} \mathrm{~s}^{-1}\right.$, calculated at the B3LYP/6-31 G* level). ${ }^{94,99,100}$ Analyzing the results of Table 3 as a function of their central rings, we have observed that: i) a balanced transport is found for derivatives 1 , with $\mathrm{k}_{\mathrm{CT}} \approx 10^{13} \mathrm{~s}^{-1}$ for both hole and electron charge transfer rates, and even higher for $1 \mathrm{P}$ compound where $\mathrm{k}_{\mathrm{CT}}{ }^{+} \approx 10^{14} \mathrm{~s}^{-1} ;$ ii) a high electron transfer rate for $2 \mathrm{~S}\left(\mathrm{k}_{\mathrm{CT}^{-}} \approx 10^{14} \mathrm{~S}^{-1}\right)$ is obtained among compounds 2 ; iii) derivatives 3 only show significant electron transfer rate in agreement with previous papers, $21,31,99,100 \mathrm{iv}$ ) an ambipolar transport could be produced for $4 \mathrm{H}, 40$ and $4 \mathrm{~T}$ compounds, being mostly hole (electron) transport for $4 \mathrm{~L}$ and $4 \mathrm{~N}$ ( $5 \mathrm{~J}$ and $\mathbf{4 S}$ ) compounds; and v) derivatives 5 also show a quasi-ambipolar transport for $\mathbf{5 H}, \mathbf{5 I}, \mathbf{5 0}, \mathbf{5 P}$ and $\mathbf{5 T}$ compounds, being however predominant the hole transport path in the case of $5 \mathrm{~L}$ and $5 \mathrm{~N}$ compounds.

\section{CONCLUSIONS}

In this work, we have theoretically studied the electronic properties of a large series of 1,4bis(phenylethynyl)benzene derivatives, employing state-of-the-art DFT calculations, and analyzed their charge injection and charge transport behavior. Regarding charge injection, almost all compounds satisfied the ohmic contact conditions with some of the most widely used electrodes such as Mg, ITO or Au. However the stability conditions imposed by the electron affinity were only satisfied for some derivatives containing the $\mathbf{P}$ moiety as substituent, being ideally $\mathbf{3 P}$ the compounds with better properties in the case of electron 
injection. In the case of hole injection, the derivatives $\mathbf{1}$ with $\mathbf{S}$ and $\mathbf{T}$ moieties in $\mathrm{X}$-position in their structure showed the lower lowest values for ionization potential, with $1 \mathrm{~S}$ the compound exhibiting the lowest one. Generally speaking, we have focused on compounds with reorganization energies equal or lower than 0.15 $\mathrm{eV}$ to determine the binding energy and the charge transfer integral, in a further step. In that sense, we found a great variety of properties: i) some compounds presented an ambipolar transport behavior such as derivatives 1 and some 4 and 5 compounds as $4 \mathrm{H}, 40,4 \mathrm{~T}, 5 \mathrm{H}, 5 \mathrm{I}, 50$ and $5 \mathrm{~T}$; ii) other compounds showed a marked electron transport behavior such as systems 3 and $2 \mathrm{~T}, 4 \mathrm{~J}$ and $4 \mathrm{~T}$; iii) a few compounds exhibited a pronounced hole transport character as $4 \mathrm{~L}, \mathbf{4 N}, 5 \mathrm{~L}$ and $\mathbf{5 N}$ derivatives. Merging both charge injection and transport behavior, we could anticipate 1P or 1T compounds as efficient $p$-semiconductors (hole transport); while we could propose $\mathbf{2} \mathbf{T}$ or $\mathbf{5 P}$ as possible $n$-type semiconductor (electron transport)

\section{SUPPORTING INFORMATION}

Supplementary Table S1 collects ionization potentials, electron affinities and reoganizations energies calculated values for all studied compounds.

Supplementary Figure S1 shows the shape of HOMOs and LUMOs of some selected compounds. Some selected binding energy lansdcapes appear in Figure S2.

\section{ACKNOWLEDGMENTS}

M. Moral thanks the E2TP CYTEMA-SANTANDER program for the financial support. Likewise, authors are grateful for the project DIPUAB-16-GARZONRUIZ financed jointly by the "Diputación de Albacete" and the "Universidad de Castilla-La Mancha". The authors also thank the "Servicio de Supercomputación de la Universidad de Castilla-La Mancha" for providing the computing time.

\section{REFERENCES}

[1] Sun, L.; Diaz-Fernández, Y.A.; Gschneidtner, T.A.; Westerlund, F.; Lara-Avila, S.; and MothPoulsen, K. Chem. Soc. Rev., 2014, 43, 7378-7411.

[2] Diederich, F.; Tykwinski, R. R.; Stang, P. J. Acetylene Chemistry: Chemistry, Biology and Material Science. Wiley, Weinheim (2005)

[3] K. Schmieder, M. Levitus, H. Dang, and M. A. Garcia-Garibay. Photophysical Properties of Coplanar and Twisted 1,4-Bis(9-ethynylanthracenyl)benzene. Rotational Equilibration in the Excited States of Diaryalkynes. J. Phys. Chem. A, 2002, 106, 1551-1556

[4] Levitus, M.; Schmieder, K.; Ricks, H.; Shimizu, K. D.; Bunz, U. F.; Garcia-Garibay, M. A. Steps To Demarcate the Effects of Chromophore Aggregation and Planarization in Poly-(phenyleneethynylene)s. 1. 
Rotationally Interrupted Conjugation in the Excited States of 1,4-Bis(phenylethynyl)benzene. J. Am. Chem. Soc., 2001, 123, 4259-4625.

[5] Beeby, A.; Findlay, K. S.; Low, F. J.; Marder, T. B. A Re-Evaluation of The Photophysical Properties of 1,4-Bis(phenylethynyl)-benzene: A Model for Poly(phenyleneethynylene). J. Am. Chem. Soc., 2002, 124, 8280-8284.

[6] Beeby, A.; Findlay, K. S.; Low, F. J.; Marder, T. B.; Matousek, P.; Parker, A. W.; Rutter, S. R.; Towrie, M. Studies of the S1, State in a Prototypical Molecular Wire Using Picosecond Time-Resolved Spectroscopies. Chem. Commun., 2003, 2406-2407.

[7] Granadino-Roldán, J. M.; Garzón, A.; García, G.; Peña-Ruiz, T.; Fernández-Liencres, M. P.; Navarro, A.; Fernández-Gómez, M. Theoretical Study of the Effect of Ethynyl Group on the Structure and Electrical Properties of Phenyl-Thiadiazole Systems as Precursors of Electron-Conducting Materials. J. Chem. Phys. 2009, 130, 234907.

[8] Garzón, A.; Granadino-Roldán, J. M.; Moral, M.; García, G.; Fernández-Liencres, M. P.; Navarro, A.; Peña-Ruiz, T.; Fernández-Gómez, M. Density Functional Theory Study of the Optical and Electronic Properties of Oligomers Based on Phenyl-Ethynyl Units Linked to Triazole, Thiadiazole, and Oxadiazole Rings To Be Used in Molecular Electronics. J. Chem. Phys. 2010, 132, 064901.

[9] Greaves, S. J.; Flynn, E. L.; Futcher, F. L.; Wrede, E.; Lydon, D. P.; Low, P. J.; Rutter, S. R.; Beeby, A. Cavity Ring-Down Spectroscopy of the Torsional Motions of 1,4-Bis(phenylethynyl)benzene J. Phys. Chem. A, 2006, 110, 2114-2121.

[10] Fasina, T. M.; Collings, J. C.; Lydon, D. P.; Albesa-Jove, D.; Batsanov, A. S.; Howard, J. A. K.; Nguyen, P.; Bruce, M.; Scott, A. J.; Clegg, W.; Watt, S. W.; Vineye, C.; Marder, T. B. Synthesis, Optical Properties, Crystal Structures and Phase Behaviour of Selectively Fluorinated 1,4-Bis(4'pyridylethynyl)benzenes, 4-(Phenylethynyl)pyridines and 9,10-Bis(4'-pyridylethynyl)-anthracene, and a $\mathrm{Zn}\left(\mathrm{NO}_{3}\right)_{2}$ Coordination Polymer. J. Mater. Chem., 2004, 14, 2395-2404

[11] Flatt, A. K.; Dirk, S.M.; Henderson, J. C.; Shen, D. E.; Su, J.; Reed, M. A.; Tour, J.M. Synthesis and Testing of New End-Functionalized Oligomers for Molecular Electronics. Tetrahedron, 2003, 59, 85558570.

[12] An, Z.; Odom, S. A.; Kelley, R. F.; Huang, C.; Zhang, X.; Barlow, S.; Padilha, L. A.; Fu, J.; Webster, S.; Hagan, D. J.; Van Stryland, E. W.; Wasielewski, M. R.; Marder, S. R. Synthesis and Photophysical 
Properties of Donor- and Acceptor-Substituted 1,7-Bis(arylalkynyl)perylene-3,4:9,10-bis(dicarboximide)s. J. Phys. Chem. A, 2009, 113, 5585-5593

[13] Hughes, G.; Bryce, M.R. Electron-Transporting Materials for Organic Electroluminescent and Electrophosphorescent Devices. J. Mater. Chem., 2005, 15, 94-107.

[14] Bunz, U. H. F. Poly(aryleneethynylene)s: Syntheses, Properties, Structures, and Applications. Chem. Rev., 2000, 100, 1605-1644

[15] Yamamoto, T.; Yamada, W.; Takagi, M.; Kizu, K.; Maruyama, T.; Ooba, N.; Tomaru, S.; Kurihara, T.; Kaino, T.; Kubota, K. m-Conjugated Soluble Poly(aryleneethynylene) Type Polymers. Preparation by Palladium-Catalyzed Coupling Reaction, Nonlinear Optical Properties, Doping, and Chemical Reactivity. Macromolecules, 1994, 27, 6620-6626.

[16] Yasuda, T.; Imase, T.; Sasaki, S.; Yamamoto, T. Synthesis, Solid Structure, and Optical Properties of New Thiophene-Based Alternating m-Conjugated Copolymers Containing 4-Alkyl-1,2,4-trazole o 1,3,4Thiadiazole Units as the Partner Unit. Macromolecules, 2005, 38, 1500-1503.

[17] Yasuda, T.; Imase, T.; Nakamura, Y.; Yamamoto, T. New Alternative Donor-Acdeptor arranged Poly(Aryleneethynylene)s and Their Related Compounds Composed of Five-Membered Electron-Accpeting 1,3,4-Thiadiazole, 1,2,4-Triazole, or 3,4-Dinitrothiophene Units: Synthesis, Packing Structure, and Optical Properties. Macromolecules, 2005, 38, 487-4697.

[18] Li, N.; Li, Z.; Zhang, X.; Hua, R. Synthesis of 1,4-Bis(phenylethynyl)benzenes and Their Application as Blue Phase Liquid Crystal Compostion. Int. J. Mol. Sci., 2013, 14, 23257-23273.

[19] QI, Y-Y.; Sun, X-H.; Chang, X-M.; Kang, R.; Liu, K-Q.; Fang, Y. A New Type of 1,4Bis(phenylethynyl)benzene Derivatives: Optical Behavior and Sensing Applications. Acta Phys. Chim. Sin., 2016, 32, 373-379.

[20] Yamaguchi, Y.; Ochi, T.; Matsubara, Y.; Yoshida, Z. Highly Emissive Whole Rainbow Fluorophores Consisting of 1,4-Bis(2-phenylethynyl)benzene Cole Skeleton: Design, Synthesis, and Light-Emitting Characteristics. J. Phys. Chem. A., 2015, 119, 8630-8642.

[21] Moral, M.; Garzón, A.; Olivier, Y.; Muccioli, L.; Sancho-García, J. C.; Granadino-Roldán, J. M.; Fernández-Gómez, M. Bis(arylene-ethynylene)-s-tetrazines: A Promising Family of n-Type Organic Semiconductors?. J. Phys. Chem. C, 2015, 119, 18945-18955. 
[22] Cheng, Y-J.; Yang, S-H.; Hsu, C-S. Synthesis of Conjugated Polymers for Organic Solar Cell Applications. Chem. Rev., 2009, 109, 5868-5923.

[23] Chochos, C.L.; Choulis, S.A. How the Structural Desviation of the Backbonoe of Conjugated Polymers Influcence Their Optoelectronic Properties and Photovaltaic Performance. Progress in Polymer Science, 2011, 1326-1414

[24] Marcus, R. A. Electron Transfer Reaction in Chemistry. Theory and Experiment. Rev. Mod. Phys., 1993, 65, 599-610.

[25] Wang, L.; Nan, G.; Yang, X.; Peng, Q.; Li, Q.; Shuai, Z. Computational Methods for Design of Organic Materials with High Charge Mobility. Chem. Soc. Rev., 2010, 39, 423-434.

[26] Coropceanu, V.; Cornil, J.; da Silva Filho, D. A.; Olivier, Y.; Silbey, R.; Brédas, J. L. Charge Transport in Organic Semiconductors. Chem. Rev., 2007, 107, 926-952

[27] Troisi, A. Charge Transport in High Mobility Molecular Semiconductors: Classical Model and New Theories. Chem. Soc. Rev., 2011, 40, 2347-2358.

[28] Barbara, P. F.; Meyer, T. J.; Ratner, M. A. Contemporary Issues in Electron Transfer Research. J. Phys. Chem., 1996, 100, 13148- 13168.

[29] Jortner, J. Temperature Dependent Activation Energy for Electron Transfer Between Biological Molecules. J. Phys. Chem., 1976, 64, 4860-4867.

[30] Moral, M.; García, G.; Garzón, A.; Granadino-Roldán, J. M.; Fernández-Gómez, M. DFT Study of the Effect of Fluorine Atoms on the Crystal Structure and Semiconducting Properties of Poly(aryleneethynylene) Derivatives. J. Chem. Phys., 2016, 144, 154902.

[31] Moral, M.; Garzón, A.; Canales-Vázquez, J.; Sancho-García, J. C. Optoelectronic and Semiconducting Properties of Conjugated Polymers Composed of Thiazolo[5,4-d]thiazole and Arene Imides Linked by Ethynylene Bridges. J. Phys. Chem. C, 2016, 120, 24583-24596.

[32] Moral, M.; García, G.; Garzón, A.; Granadino-Roldán, J. M.; Fox, M. A.; Yufit, D. S.; Peñas, A.; Melguizo, M.; Fernández-Gómez, M. Electronic Structure and Charge Transport Properties of a Series of 
3,6-(Diphenyl)-s-tetrazine Derivatives: Are They Suitable Candidates for Molecular Electronics? J. Phys. Chem. C, 2014, 118, 26427-26439.

[33] McMahon, D. P.; Troisi, A. Evaluation of External Reorganization Energy of Polyacenes. J. Phys. Chem. Lett., 2010, 1, 941-946.

[34] Martinelli, N. G.; Idé, J.; Sánchez-Carrera, R. S.; Coropceanu, V.; Brédas, J. L.; Ducasse, L.; Castet, F.; Cornil, J.; Beljonne, D. Influence of Structural Dynamics on Polarization Energies in Anthracene Single Crystals. J. Phys. Chem. C, 2010, 114, 20678-20685.

[35] Newman, C. R.; Frisbie, C. D.; da Silva Filho, D. A.; Brédas, J. L.; Ewbank, P. C.; Mann, K. R. Introduction of Organic Thin Film Transistors and Design of n-Channel Organic Semiconductors. Chem. Mater., 2004, 16, 4436-4451.

[36] Chen, H. Y.; Chao, I. Effect of Perfluorination on the Charge-Transport Properties of Semiconductors: Density Functional Theory Study of Perfluorinated Pentacene and Sexithiophene. Chem. Phys. Lett., 2005, 401, 539-545.

[37] Brédas, J. L.; Beljonne, D.; Coropceanu, V.; Cornil, J. Charge-Transfer and Energy-Transfer Process in $\pi$-Conjugated Oligomers and Polymers: A Molecular Picture. Chem. Rev., 2004, 104, 4971-5004.

[38] Coropceanu, V.; André, J. M.; Malagoli, M.; Brédas, J. L. The Role of Vibronic Interactions on Intramolecular and Intermolecular Electron Transfer in m-Conjugated Oligomers. Theor. Chem. Acc., 2003, $110,59-69$.

[39] Norton, J. E.; Brédas, J. L. Polarization Energies in Oligoacene Semiconductor Crystals. J. Am. Chem. Soc., 2008, 130, 12377-12384.

[40] Martinelli, N. G.; Savini, M.; Muccioli, L.; Olivier, Y.; Castet, F.; Zannoni, C.; Beljonne, D.; Cornil, J. Modeling Polymer Dielectric/Pentacene Interfaces: On the Role of Electrostatic Energy Disorder on Charge Carrier Mobility. Adv. Funct. Mater., 2009, 19, 3254-3261.

[41] Lemaur, V.; Steel, M.; Beljonne, D.; Brédas, J. L.; Cornil, J. Photoinduced Charge Generation and Recombination Dynamics in Model Donor/Acceptor Pairs for Organic Solar Cell Applications: A Full Quantum-Chemical Treatment. J. Am. Chem. Soc., 2005, 127, 6077-6086. 
[42] Nan, G.; Yang, X.; Wang, L.; Shuai, Z.; Zhao, Y. Nuclear Tunneling Effects of Charge Transport in Rubrene, Tetracene and Pentacene. Phys. Rev. B: Condens. Matter Mater. Phys. 2009, 79, 1152031-115203-9.

[43] Geng, H.; Peng, Q.; Wang, L.; Li, H.; Liao, Y.; Ma, Z.; Shuai, Z. Towards Quantitative Prediction of Charge Mobility in Organic Semiconductors: Tunneling Enabled Hopping Model. Adv. Mater. 2012, 24, 3568-3572.

[44] Stehr, V.; Fink, R. F.; Tafipolski, M.; Deibel, C.; Engels, B. Comparison of Different Rate Constant Expressions for the Prediction of Charge and Energy Transport in Oligoacenes. WIREs Comput. Mol. Sci. 2016, 6, 694-720

[45] Liu, T.; Troisi, A. Absolute Rate of Charge Separation and Recombination in Molecular Model of the P3HT/PCBM Interface. J. Phys. Chem. C, 2011, 115, 2406-2415.

[46] Moral, M.; Pérez-Jiménez, A.J.; Sancho-García, J.C. Understanding and Controlling Chemical Modifications of Rubicene for Their Envisioned Use as Molecular Organic Semiconductors. J. Phys. Chem. C, 2017, 121, 3171-3181

[47] Olivier, Y.; Lemaur, V.; Brédas, J. L.; Cornil, J. Charge Hopping in Organic Semiconductors: Influence of Molecular Parameters on Macroscopic Mobilities in Model One-Dimensional Stacks. J. Phys. Chem. A, 2006, 110, 6356-6364.

[48] Burquel, A.; Lemaur, V.; Beljonne, D.; Lazzaroni, R.; Cornil, J. Pathways for Photoinduced Charge Separation and Recombination at Donor-Acceptor Heterojunctions: The Case of OligophenylenevinylenePerylene Bisimide Complexes. J. Phys. Chem. A, 2006, 110, 3447-3453.

[49] Nelsen, S. F.; Yunta, M. J. R. Estimation of Marcus $\lambda$ for $p$-Phenylenediamines from the Optical Spectrum of a Dimeric Derivative. J. Phys. Org. Chem., 1994, 7, 55-62.

[50] Nelsen, S. F.; Blackstock, S. C.; Kim, Y. Estimation of Inner Shell Marcus Terms for Amino Nitrogen Compounds by Molecular Orbital Calculations. J. Am. Chem. Soc., 1987, 109, 677-682.

[51] Viani, L.; Oliver, Y.; Athanasopoulus, S.; da Silva Filho, D. A.; Hulliger. J.; Bredas, J.; Gierschner, J.; Cornil, J. Theoretical Characterization of Charge Transport in One-Dimensional Collinear Arrays of Organic Conjugated Molecules. ChemPhysChem, 2010, 11, 1062- 068. 
[52] Chai, S.; Wen, S.H.; Huang, J.D.; Han, K.L. Density Functional Theory Study on Electron and Hole Transport Properties of Organic Pentacene Derivatives with Electron-Withdrawing Substituent. J. Comput. Chem., 2011, 32, $3218-3225$.

[53] Chen, X. K.; Zou, L. Y.; Guo, J. F.; Ren, A. M. An Efficient Strategy for Designing n-Type Organic Semiconductor Materials-Introducing a Six-Membered Imide Ring into Aromatic Diimides. J. Mater. Chem., 2012, 22, $6471-6484$.

[54] Geng, Y.; Wang, J.; Wu, S.; Li, H.; F. Yu, G. Yang, H. Gao and Z. Su. Theoretical Discussions on Electron Transport Properties of Perylene Bisimide Derivatives with Different Molecular Packings and Intermolecular Interactions. J. Mater. Chem., 2011, 21, 134-143.

[55] Ishii, H.; Sugiyama, K.; Ito, E.; Seki, K. Energy Level Alignment and Interfacial Electronic Structures at Organic/Metal and Organic/Organic Interfaces. Adv. Mater., 1999, 11, 605-625.

[56] Zaumseil, J.; Sirringhaus, H. Electron and Ambipolar Transport in Organic Field-Effect Transistors. Chem. Rev., 2007, 107, 1296-323.

[57] Körzdörfer, T.; Parrish, R. M.; Sears, J. S.; Sherrill, C. D.; Brédas, J. L. On the relationship between bond-length alternation and many-electron self-interaction error. J. Chem. Phys., 2012, 137, 124305.

[58] Sancho-García, J. C. Application of Double-Hybrid Density Functionals to Charge Transfer in NSubstituted Pentacenequinones. J. Chem. Phys., 2012, 136, 174703.

[59] Louis, E.; San-Fabián, E.; Díaz-García, M.A.; Chiappe, G.; Vergés, J.A. Are Electron Affinity and Ionization Potential Intrinsic Parameters to Predict the Electron or Hole Acceptor Character of Amorphous Molecular Materials? J. Phys. Chem. Lett., 2017, 8, 2445 - 2449

[60] Wang, Y.; Parkin, S. R.; Gierschner, J.; Watson, M. D. Highly Fluorinated Benzobisbenzothiophenes. Org. Lett., 2008, 10, 3307-3310.

[61] Anthopoulos, T.D.; Anyfantis, G.C.; Papavassiliou, G.C.; de Leeuw, D.M. Air Stable Ambipolar Organic Transistor. Appl. Phys. Lett., 2007, 90, 122105.

[62] Zhan, X.; Faccetti, A.; Barlow, S.; Mark, T.J.; Ratner, M.A.; Wasielewski, M.R.; Marder, S.R. Rylene and Related Diimides for Organic Electronics. Adv. Mater., 2011, 23, 268 - 284 
[63] Jones, B. A.; Facchetti, A.; Wasielewski, M. R.; Marks, T. J. Tuning Orbital Energetics in Arylene Diimide Semiconductors. Materials Design for Ambient Stability of $n$-Type Charge Transport. J. Am. Chem. Soc., 2007, 129, 15259-15278.

[64] Chang, Y. C.; Kuo, M. Y.; Chen, C. P.; Lu, H. F.; Chao, I. On the Air Stability of n-Channel Organic Field-Effect Transistors: A Theoretical Study of Adiabatic Electron Affinities of Organic Semiconductors. J. Phys. Chem. C, 2010, 114, 11595-11601.

[65] Schmidt, R.; Oh, J. H.; Sun, Y. S.; Deppisch, M.; Krause, A. M.; Radacki, K.; Braunscheweig, H.; Konemann, M.; Erk, P.; Bao, Z.; et al. High-Performance Air-Stable n-Channel Organic Thin Film Transistor Based on Halogenated Perylenebismide Semiconductors. J. Am. Chem. Soc., 2009, 131, 6215-6228.

[66] Frisch, M. J.; Trucks, G. W.; Schlegel, H. B.; Scuseria, G. E.; Robb, M. A.; Cheeseman, J. R.; Scalmani, G.; Barone, V.; Mennucci, B.; Petersson, G. A.; et al. Gaussian 09; Gaussian, Inc., Wallingford CT, 2009.

[67] Foresman, J.B.; Frisch, A.E. Exploring Chemistry with Electronic Structure Methods, 2nd ed., Gaussian Inc., Pittsburgh, PA, 1996.

[68] Jansson, E.; Jha, P. C.; Ågren, H. Density Functional Study of Triazole and Thiadiazole Systems as Electron Transporting Materials. Chem. Phys., 2006, 330, 166-171.

[69] Dreizler, R. M.; Providênca, J. Density Functional Methods in Physics; Plenum Press: New York; London, 1985.

[70] Rienstra-Kiracofe, J. C.; Barden, C. J.; Brown, S. T.; Schaefer, H. F. Electron Affinities of Polycyclic Aromatic Hydrocarbons. J. Phys. Chem. A, 2001, 105, 524-528.

[71] Zhan, C. G.; Nichols, J. A.; Dixon, D. A. Ionization Potential, Electron Affinity, Electronegativity, Hardness and Electron Excitation Energy: Molecular Properties from Density Functional Theory Orbital Energies. J. Phys. Chem. A, 2003, 107, 4184-4195.

[72] Coropceanu, V.; Malagoli, M.; da Silva Filho, D. A.; Gruhn, N. E.; Bill, T. G.; Brédas, J. L. Hole- and Electron-Vibrational Couplings in Oligoacene Crystals: Intramolecular Contributions. Phys. Rev. Lett., 2002, 89, 275503-275507. 
[73] Zhang, G.; Musgrave, C. B. Comparison of DFT Methods for Molecular Orbital Eigenvalue Calculations. J. Phys. Chem. A, 2007, 111, 1554-1561.

[74] Zhao, Y.; Truhlar, D. G. The M06 Suite of Density Functional for Main Group Thermochemistry, Thermochemical Kinetics, Non-Covalent Interactions, Excited States, and Transition Elements: Two New Functional and Systematic Testin of Four M06-class Functional and 12 other Functionals. Theor. Chem. Acc. 2008, 120, 215-241

[75] Roothaan, C. C. J. New Developments in Molecular Orbital Theory. Rev. Mod. Phys. 1951, 23, 69

[76] Kumar, S. Chemistry of Discotic Liquid Crystals. From Monomers to Polymers; CRC Press, 2011.

[77] Vura-Weis, J.; Ratner, M. A.; Wasielewski, M. R. Geometry and Electronic Coupling in Perylenediimide Stacks: Mapping Structure- Charge Transport Relationships. J. Am. Chem. Soc., 2010, 132, 1738-1739.

[78] Liu, H.; Bremond, E.; Prlj, A.; Gonthier, J. F.; Corminboeuf, C. Adjusting the Local Arrangement of $\pi$-Stacked Oligothiophenes through Hydrogen Bonds: A Viable Route To Promote Charge Transfer. J. Phys. Chem. Lett., 2014, 5, 2320-2324.

[79] Hohenstein, E. G.; Chill, S. T.; Sherrill, C. D. Assessment of the Performance of the M05-2X and M06-2X Exchange-Correlation Functionals for Noncovalent Interaction in Biomolecules. J. Chem. Theory Comput. 2,008, 4, 1996-2000.

[80] Cheng, X.; Noh, Y. Y.; Wang, J.; Tello, M.; Frisch, J.; Blum, R. P.; Vollmer, A.; Rabe, J. P.; Koch, N. T.; Sirringhaus, H. Controlling Electron and Hole Charge Injection in Ambipolar Organic Field-Effect Transistors by Self-Assembled Monolayers. Adv. Funct. Mater., 2009, 19, 2407-2415.

[81] Amy, F.; Chan, C.; Kahn, A. Polarization at The Gold/Pentacene Interface. Org. Electron. 2005, 6, 85-91.

[82] Lee, H.; Zhang, Y.; Zhang, L.; Mirabito, T.; Burnett, E.K.; Trahan, S.; Mohebbi, A.R.; Mannsfeld, S.C.B.; Wudl, F.; Briseno, A.L. Rubicene. A Molecular Fragment of $\mathrm{C}_{70}$ for Use in Organic Field Effect Transistors. J. Mater. Chem. C., 2014, 2, $3361-3366$

[83] Michaelson, H. B. The Work Function of the Elements and its Periodicity. J. Appl. Phys. 1977, 48, 4729-4733. 
[84] Sun, S. S.; Dalton, L. R. Introduction to Organic Electronic and Optoelectronic Materials and Devices; CRC Press, Taylor \& Francis Group: New York, 2005.

[85] Greiner, M. T.; Chai, L.; Helander, M. G.; Tang, W. M.; Lu, Z.-H. Transition Metal Oxide Work Functions: The Influence of Cation Oxidation State and Oxygen Vacancies. Adv. Funct. Mater., 2012, 22, 4557-4568.

[86] Greiner, M. T.; Lu, Z.-H. Thin-film Metal Oxides in Organic Semiconductor Devices: Their Electronic Structures, Work Functions and Interfaces. NPG Asia Mater. 2013, 5, e55

[87] Körzdörfer, T.; Brédas, J.L. Organic Electronic Materials: Recent Advances in the DFT Description of the Ground and Excited States Using Tuned Range-Separated Hybrid Functionals. Acc. Chem. Res., 2014, 47, 3284-3291.

[88] Renz, M.; Theilacker, K.; Lambert, C.; Kaupp, M. A Reliable Quantum-Chemical Protocol for the Characterization of Organic Mixed-Valence Compounds. J. Am. Chem. Soc. 2009, 131, 16292-16302.

[89] Koh, S. E.; Risko, C.; da Silva Filho, D. A.; Kwon, O.; Facchetti, A.; Brédas, J. L.; Marks, T. J.; Ratner, M. A. Modelling Electron and Hole Transport in Fluoroarene-Oligothiopene Semiconductors: Investigation of Geometric and Electronic Structure Properties. Adv. Funct. Mater., 2008, 18, 332-340.

[90] Ma, H.; Liu, N.; Huang, J. D. A DFT Study on the Electronic Structures and Conducting Properties of Rubrene and its Derivatives in Organic Field-Effect Transistors. Sci. Reports, 2017, 7, 331.

[91] Sancho-García, J.C.; Moral, M.; Pérez-Jimenez, A.J. Effect of Cyclic Topology on Charge-Transfer Properties of Organic Molecular Semiconductors: The case of Cycloparaphenylene Molecules. J. Phys. Chem. C, 2016, 120, 9104-9111

[92] Otón, F.; Pfattner, R.; Pavlica, E.; Olivier, Y.; Moreno, E.; Puigdollers, J.; Bratina, G.; Cornil, J.; Fontrodona, X.; Mas-Torrent, M.; et al. Electron-Withdrawing Substituted Tetrathiafulvalenes as Ambipolar Semiconductors. Chem. Mater., 2011, 23, 851-861

[93] Sokolov, A. N.; Atahan-Evrenk, S.; Mondal, R.; Akkerman, H. B.; Sánchez-Carrera, R. S.; Granados-Focil, S.; Schrier, J.; Mannsfeld, S. C. B.; Zoombelt, A. P.; Bao, Z.; Aspuru-Guzik, A. From Computational Discovery to Experimental Characterization of a High Hole Mobility Organic Crystal. Nature Commun. 2011, 437, 1-8 
[94] Canola, S.; Negri, F. The Role of the HOMO-1 Orbital on the p-Type Charge Transport of the FusedRing Thienoacene DBTDT. J. Phys. Chem. C 2015, 119, 11499-11505

[95] Zhu, L.; Geng, H.; Yi, Y.; Wei, Z. Charge Transport in Organic Donor-Acceptor Mixed-Stack Crystals: The Role of Nonlocal Electron-Phonon Couplings. Phys. Chem. Chem. Phys., 2016, 19, 44184425.

[96] Nan, G.; Wang, L.; Yang, X.; Shuai, Z.; Zhao, Y. Charge Transfer Rate in Organic Semiconductors Beyond First-Order Perturbation: From weak to Strong Coupling Regimes. J. Chem. Phys., 2009, 130, 024704.

[97] Fan, J-X.; Chen, X-K.; Zhang, S-F.; Ren, A-M. Theoretical Study on Charge Transport Properties of Intra- and Extra Ring Substituents Pentacene Derivatives. J. Phys. Chem. A. 2015, 120, 2390 - 2400

[98] Wang, C.; Wang, F.; Yang, X.; Li, Q.; Shuai, Z. Theoretical Comparative Studies of Charge Mobilities for Molecular Materials: PET vs Bnpery. Org. Electron., 2008, 9, 635 - 640.

[99] Di Donato, E.; Fornari, R.P.; Di Motta, S.; Li, Y.; Wang, Z.; Negri, F. n-Type Charge Transport and Mobility of Fluorinated Perylene Bisimide Semiconductors. J. Phys. Chem. B, 2010, 114, 5327 - 5334.

[100] Di Motta, S.; Di Donato, E.; Negri, F.; Orlandi, G.; Fazzi, D.; Castiglioni, C. Resistive Molecular Memories: Influence of Molecular Parameters on the Electrical Bistability. J. Am. Chem. Soc., 2009, 131, 6591-6598 